\title{
Comparing Different Fault Identification Algorithms in Distributed Power System
}

\author{
Salim Alkaabi
}

Follow this and additional works at: https://researchrepository.wvu.edu/etd

\section{Recommended Citation}

Alkaabi, Salim, "Comparing Different Fault Identification Algorithms in Distributed Power System" (2015). Graduate Theses, Dissertations, and Problem Reports. 5070.

https://researchrepository.wvu.edu/etd/5070

This Thesis is protected by copyright and/or related rights. It has been brought to you by the The Research Repository @ WVU with permission from the rights-holder(s). You are free to use this Thesis in any way that is permitted by the copyright and related rights legislation that applies to your use. For other uses you must obtain permission from the rights-holder(s) directly, unless additional rights are indicated by a Creative Commons license in the record and/ or on the work itself. This Thesis has been accepted for inclusion in WVU Graduate Theses, Dissertations, and Problem Reports collection by an authorized administrator of The Research Repository @ WVU. For more information, please contact researchrepository@mail.wvu.edu. 


\title{
Comparing Different Fault Identification Algorithms in Distributed Power System
}

\section{Salim Alkaabi}

Thesis submitted to the

Lane Department of Computer Science and Electrical Engineering At West Virginia University

In partial fulfillment of the requirements for the degree of Master of Science in Electrical Engineering

\author{
Dr. Muhammad A. Choudhry, Chair \\ Dr. Ali Feliachi \\ Dr. Hany H. Ammar
}

Lane Department of Computer Science and Electrical Engineering

Morgantown, West Virginia 2015

Fault Identification, Power System, Algorithms, Faults Salim Alkaabi 2015 


\title{
ABSTRACT \\ Comparing Different Fault Identification Algorithms in Distributed Power System
}

Salim Alkaabi

\begin{abstract}
A power system is a huge complex system that delivers the electrical power from the generation units to the consumers. As the demand for electrical power increased, distributed power generation was introduced to the power system. Faults may occur in the power system at any time in different locations. These faults cause a huge damage to the system as they might lead to full failure of the power system. Using distributed generation in the power system made it even harder to identify the location of the faults in the system.

The main objective of this work is to test the different fault location identification algorithms while tested on a power system with the different amount of power injected using distributed generators. As faults may lead the system to full failure, this is an important area for research.

In this thesis different fault location identification algorithms have been tested and compared while the different amount of power is injected from distributed generators. The algorithms were tested on IEEE 34 node test feeder using MATLAB and the results were compared to find when these algorithms might fail and the reliability of these methods.
\end{abstract}




\section{Acknowledgements}

Firstly, I would like to thank my Master committee chair and my advisor Dr. Muhammad A. Choudhry. It was a blessing for me to be one of his Master students and conducting research with him. I would also like to thank Dr. Ali Feliachi and Dr. Hany H. Ammar for their constructive comments and for their courses, which helped me in this research.

I would also like to present my sincere thanks to West Virginia University and its staff for helping my through my time in the university and for providing all the wonderful facilities and services, which helped me during my research and life in the city of Morgantown.

Finally, I would like to thank my mother, my soul mate, my brothers and sister and my friends, who supported me all throughout my life. Whenever I needed their support, they were always there for me with their love. 


\section{Table of Contents}

Abstract

Acknowledgment

II

Table of Contents

III

List of Figures

V

List of Tables

VI

Abbreviations

VIII

1. Chapter 1 - Introduction

1.1. Background 1

1.2. Problem Statement 2

1.3. Approach 3

1.4. Thesis Structure 4

2. Chapter 2 - Literature Review 5

2.1. Distributed Power Generation 5

$\begin{array}{ll}\text { 2.2. Fault location Methods } & 6\end{array}$

2.2.1. Measuring Fundamental Quantities of DPS 6

$\begin{array}{ll}\text { 2.2.2. Knowledge-Based Methods } & 8\end{array}$

2.3. Fault Types 9

3. Chapter 3 - Modeling And Simulation 10

$\begin{array}{ll}\text { 3.1. Simulation Software } & 11\end{array}$

3.2. Modeling the Test Feeder 11 
3.2.1. Modeling Transmission lines

3.2.2. Modeling and Testing the Simulation

3.2.3. Identifying the Zones

3.3. Fault Types Simulated

4. Chapter 4-Algorithms for Fault Identification

4.1. Change of Current

4.1.1. Change of Current Equations

4.1.2. Change of Current Algorithm

4.2. Symmetrical Components

4.2.1. Symmetrical Components Equations

4.2.2. Symmetrical Components Algorithm 23

4.3. Artificial Neural Network

25

4.3.1. Structure of ANN

26

4.3.2. Training and Target Data for ANN

4.3.3. Training ANN

5. Chapter 5-Testing and Results

5.1. Testing the system with no Faults

5.2. Results using Change of Current Method 36

5.3. Results using Symmetrical Components Method

5.4. Results using ANN

6. Chapter 6 - Conclusion and Future Work 55

6.1. Conclusion 55

6.2. Future Work 57 


\section{List of Figures}

1. Single-Line Diagram of IEEE 34 Node Test Feeder 10

2. Overhead lines spacing ID 13

3. SIMULINK Model of IEEE 34 Node Test Feeder 16

4. Division of the Zones in the Simulated Model 17

5. Change of Current Algorithm Flow Chart 20

6. Symmetrical Component Method Flow Chart 23

7. Structure of ANN 26

8. ANN Training Performance 29

9. Measurements block location and label 31 


\section{List of Tables}

1. Overhead Line Configurations (Config.) 12

2. Line Segment Data 12

3. Conductor Data 13

$\begin{array}{lr}\text { 4. Overhead Lines Spacing } & 13\end{array}$

5. Three Phase Transmission Line Model Parameters 14

6. Single Phase Transmission Line Model Parameters 14

7. Voltage and Current for PDS with no DG and no faults 32

8. Voltage and Current for PDS with 25\% DG and no faults 33

9. Voltage and Current for PDS with 50\% DG and no faults 34

10. Voltage and Current for PDS with 75\% DG and no faults 35

11. Change of Current Method with 3-phase Fault in Zone 2

12. : Change of Current Method with 3-phase Fault in Zone 5

13. Change of Current Method with Line-Line (A, B) Fault in Zone 2

14. Change of Current Method with Line-Line (A, B) Fault in Zone 5

15. Change of Current Method with 3-phase Fault in Zone 2 through

$\begin{array}{ll}\text { 10-ohm resistance } & 39\end{array}$

16. Change of Current Method with 3-phase Fault in Zone 5 through $\begin{array}{ll}\text { 10-ohm resistance } & 39\end{array}$

17. Change of Current Method with single phase Fault in Zone $2 \quad 40$

18. Change of Current Method with single phase Fault in Zone $5 \quad 40$

19. Symmetrical Components Method with 3-phase Fault in Zone 2

20. Symmetrical Components Method with 3-phase Fault in Zone 5

21. Symmetrical Components Method with Line-Line (A, B) Fault in Zone 2

22. Symmetrical Components Method with Line-Line (A, B) Fault in Zone 5 
23. Symmetrical Components Method with 3-phase Fault in Zone 2 through 10-ohm resistance

24. Symmetrical Components Method with 3-phase Fault in Zone 5 through 10-ohm resistance

25. Symmetrical Components Method with single phase to ground

Fault in zone 2

26. Symmetrical Components Method with single phase to ground Fault in zone 5

27. Training Data and Result with no DG for 3-phase Fault and LL Fault

48

28. Training Data and Result with 25\% DG for 3-phase Fault and LL Fault

29. Training Data and Result with 50\% DG for 3-phase Fault and LL Fault

30. Training Data and Result with 75\% DG for 3-phase Fault and LL Fault

31. Training Data and Result with no DG for 3-phase Fault through 10-ohm resistance

32. Training Data and Result with 25\% DG for 3-phase Fault through 10-ohm resistance

33. Training Data and Result with 50\% DG for 3-phase Fault through 10-ohm resistance

34. Training Data and Result with 75\% DG for 3-phase Fault through

35. Training Data and Result with no DG for single phase to ground Fault

36. Training Data and Result with 25\% DG for single phase to ground Fault

37. Training Data and Result with $50 \%$ DG for single phase to ground Fault 


\section{Abbreviations}

\begin{tabular}{ll} 
PDS & Power Distribution system \\
DPG & Distributed Power Generation \\
ANN & Power System \\
DGs & Artificial Neural Network \\
I & Distributed Generators \\
V & Current \\
Z & Voltage \\
FZ & Impedance \\
ES & Fuzzy Logic \\
3ph & Expert System \\
LL & Three Phase \\
\hline
\end{tabular}




\section{Chapter 1}

\section{Introduction}

\subsection{Background}

Power systems are one of the most complicated systems in electrical industries. The purpose of this system is to supply electrical power to different consumers. The system consists of three main elements, which are a generation, transmission, and distribution. In the early days, these three elements were integrated for monitoring and controlling the power system (PS). As the demand for electricity increased, restructuring of the PS was necessary to be able to control the system and manage all of the elements in the system.

Distributed Generation was introduced to the PS to compensate for the power demand at the distribution level. Distributed Generators (DGs) can be considered as local power generation units at distribution level that can be used to compensate for the shortage of power in that level. Introducing the DGs has complicated the PS, so new methods need to be implemented to maintain the stability of the PS [26]. 
The PS is a huge network and faults can occur easily in the system. These faults can shut down the PS of a large area. The cascade effect is the main reason that can make the fault essentially shut down the whole system. One example is the Northeast blackout that affected around 55 million people and caused 6 billion dollars of financial losses in 14-15 Aug 2003 in USA and Canada [7]. Researchers started to focus more on this area in electrical engineering to increase the reliability of power systems and to find new methods for identifying the location of the faults in the system that might cause the system to shut down.

\subsection{Problem Statement}

In this thesis, an IEEE 34 Node test Feeder has been used to test the different fault-identifying algorithms that were used to identify the faults locations. The IEEE 34 Node test feeder has been simulated in MATLAB for the testing. The compared identification methods can be categorized into two main categories:

1. Measuring Fundamental quantities of DPS

2. Knowledge-Based Methods

The test feeder has been tested for $0 \%, 25 \%, 50 \%$ and $75 \%$ of power injected using DGs in different nodes in the system. 
The test system divided the IEEE 34 Node test feeder into 5 zones. Measuring elements were placed at the beginning and end of each zone. Current and voltage data are continuously monitored for all of the zones. When a fault occurs in the system, the data will be gathered and analyzed to find the location of the fault and identify the zone affected by that fault.

Assumptions made in this thesis are listed below:

- Transmission Lines are Transposed

- The fault will occur in one of two zones (Zone 2 or Zone 5)

- The Distributed Generators will be implemented in specific places

\subsection{Approach}

To test the methods for identifying the fault location, the IEEE 34 NTF was modeled and simulated in MATLAB-SIMULINK. The suggested methods were implemented using SIMULINK to gather the data for further analyzing. The data gathered from SIMULINK was used in the separate calculation according to each method suggested. Details of each method and the calculation needed are provided in Chapter 4.

After getting the result from each method, these methods were compared in different scenarios to find the advantage and disadvantage of each method. The tests were repeated for each method to ensure the accuracy of the data 
gathered. The methods were modified to obtain the highest accuracy and reliability.

\subsection{Thesis Structure}

The rest of the thesis was organized as follows. Chapter 2 provides a literature review of the most important researches that have been done in this area of fault location identification and the different approaches used. Chapter 3 shows the modeling and simulation process that has been used in this thesis. The Test Feeder is modeled to verify the results to make sure that the modeling is done correctly. Chapter 4 illustrates the methods used and the algorithm of each method. Also, it provides detailed information about each method used and how the method was implemented in testing it. Testing and gathering the results along with the analysis of the results gathered are presented in chapter 5 . Finally a conclusion and a scope for future work are described in Chapter 6. 


\section{Chapter 2}

\section{Literature Review}

\subsection{Distributed Power Generation}

Distributed power generation (DPG) is commonly used these days due to its advantages in supplying the power to the required places and reducing the power loss along the transmission lines. These systems have been used for the past few years more often, but the main issue with using these systems is the difficulties in identifying the fault location. Although many pieces of research have been done in the area of identifying the location of the faults on Radial power system and methods used in these systems are reliable, these methods fail to identify the fault location with distributed power generation.

The proposed system is the IEEE 34 Node system, which is an actual feeder located in Arizona. The feeder is characterized by:

- Very long and lightly loaded

- An in-line transformer reducing the voltage to $4.16 \mathrm{kV}$ for a short section of the feeder

- Unbalanced loading with both "spot" and "distributed" loads. Distributed loads are assumed to be connected at the center of the line segment 
- Shunt capacitors

And the nominal feeder voltage is $24.9 \mathrm{KV}[6]$.

This feeder will be simulated in MATLAB and different methods for locating the faults will be tested while injecting the power with Distributed Generators (DG) to test the methods. The feeder will be injected with $25 \%, 50 \%$ and $75 \%$ of power using DG.

\subsection{Fault location Methods}

Considering the characteristics of the IEEE test feeder, the unbalanced loads and the power injection at different location, identifying the fault location is a challenging task. In order to get the best results different methods will be used and these methods can be categorized into two main categories:

1. Measuring Fundamental quantities of DPS

2. Knowledge-Based Methods

\subsubsection{Measuring Fundamental}

\section{Quantities of DPS}

These methods measure the fundamental quantities of the system such as:

- Current (I)

- Voltage (V) 
- Impedance (Z)

Using one of the above-described elements, an iterating algorithm can estimate the location of the fault in the DPS. These methods have been used in the past on radial PS. However, in this research we will study the behavior of these methods when a DG power is injected into the system [8][14][22][25].

In [1] a change of current is used to estimate the location of the fault. The current is continuously monitored. The system will detect the change of the current and if the current exceeds the threshold, the system will identify the location of the fault.

As a fault occurs, the impedance of the zone (location of the faulted area) will change. The impedance of different zones in the system is calculated and monitored for any change. The change of the impedance can determine the location of the fault.

These methods are reliable and accurate in identifying the fault location, but after injecting the PS with a different amount of DG power these methods will fail. Due to limitations of these methods, they should be used in only specific PS.

In [2] the symmetrical components of the current will be calculated (Positive sequence, Negative Sequence and Zero Sequence) and the symmetrical components will be used to identify the location of the fault in PDS.

The proposed method that will be used in this thesis is the change of current, which was proposed in [1] and the symmetrical components proposed in [2]. 


\subsubsection{Knowledge-Based Methods}

These methods are also called the Artificial Intelligence methods. They required stored information of the system before they can work. Different methods in this category are used to determine the location of the faults, although the methods may vary in the implementation way. They all require information about the system before they can work. Artificial Neural Network (ANN), Fuzzy Logic (FZ) and Expert Systems (ES) are the frequent methods used in identifying the faults location [3][4][16][12][13].

These methods are reliable in different scenarios that can occur in the PS even if DGs are connected with PS. These methods need training before they can be used. The training is a mandatory procedure for these methods, and the number of the training that is done can improve the accuracy of the methods.

The proposed method that will be used in this thesis is the ANN. This method needs installation of some faults in different location in the PS and recording of all the current reading, and then the ANN is trained to identify the location of the fault [4][18][19][20]. 


\section{3 ault Types}

Different fault types can occur in the PS, and each type of these faults will affect the system in a different way. The types of faults that will be studied in this thesis are:

- Three-phase to ground Faults (3ph)

- $\quad$ Line to Line Faults (LL)

- Single-phase to ground Faults

The previously described methods should be able to identify the location and the type of the fault. The behavior of the methods will be tested for each fault type to determine which method can be most reliable for future implementation in the PS. 


\section{Chapter 3}

\section{Modeling and Simulation}

A choice of the right software is needed to simulate the IEEE 34 Node Test Feeder and identify the faults. There are several softwares used for PS, and they have different advantages and disadvantages.

Modeling the Test Feeder will differ from one simulation software to another. Each part of the test feeder will be modeled in the software and tested to ensure the accuracy of the model even before implementing the method to identify the location of the faults.

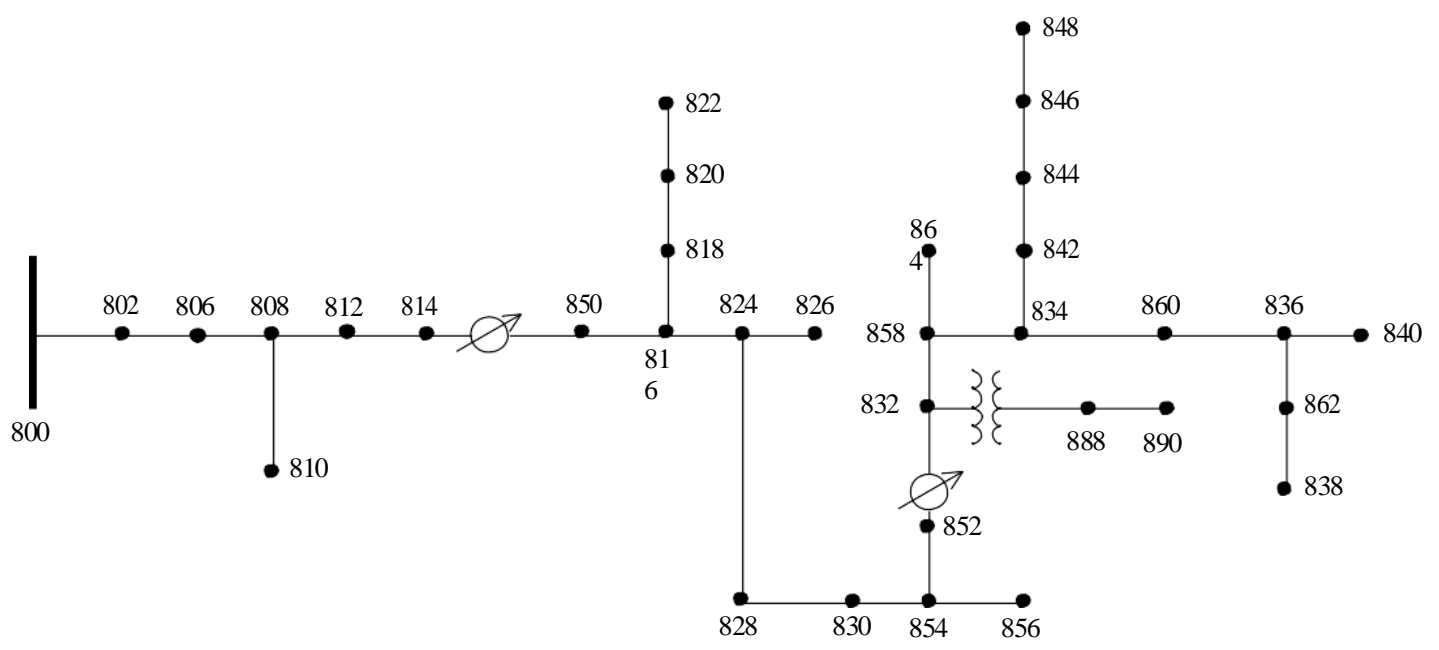

Figure 1: Single-Line Diagram of IEEE 34 Node Test Feeder 


\subsection{Simulation Software}

The simulation software used to simulate the IEEE 34 Node feeder in figure 1 is SIMULINK MATLAB. This software can easily model a power system using the SIMULINK pre-identified blocks in the power system library. MATLAB can find the steady-state values for the Test Feeder that will be used later in the algorithm for identifying the location of the fault.

The identifying algorithm will be executed as MATLAB M-File function, and the simulation will display the location of the fault for each different scenarios. The Test Feeder will be divided into zones (Zone 1 through Zone 5) and the faults will be tested on Zone 2 and Zone 4. Measurements of the required element will be taken from the beginning and ending location of the Zones and the methods of identifying the faults will use these measurements.

\subsection{Modeling the Test Feeder}

As the Test Feeder has different parts to be modeled such as transmission line, power sources and loads, each part of the Feeder should be modeled separately. After modeling the required parts from the Test Feeder, the model will be divided into the required zones and will be tested to ensure the accuracy of the model. 


\subsubsection{Modeling Transmission Lines}

The PI-Model will be used to model the transmission lines connecting the nodes in the Test Feeder. To find the required parameters for the PI-Model, some calculation will be required. Calculation of the zero and positive sequence resistance, inductance and capacitance for each configuration of the transmission lines is needed. The figure and tables provided below will be used in the calculations of the parameters for the transmission lines.

Table 1: Overhead Line Configurations (Config.)

\begin{tabular}{|c|c|c|c|c|}
\hline Config. & Phasing & Phase & Neutral & Spacing ID \\
\hline & & ACSR & ACSR & \\
\hline 300 & B A C N & $1 / 0$ & $1 / 0$ & 500 \\
\hline 301 & B A C N & $\# 26 / 1$ & $\# 26 / 1$ & 500 \\
\hline 302 & A N & $\# 46 / 1$ & $\# 46 / 1$ & 510 \\
\hline 303 & B N & $\# 46 / 1$ & $\# 46 / 1$ & 510 \\
\hline 304 & B N & $\# 26 / 1$ & $\# 26 / 1$ & 510 \\
\hline
\end{tabular}

Table 2: Line Segment Data

\begin{tabular}{|c|c|c|c|}
\hline Node A & Node B & Length (ft.) & Config. \\
\hline 800 & 802 & 2580 & 300 \\
\hline 802 & 806 & 1730 & 300 \\
\hline 806 & 808 & 32230 & 300 \\
\hline 808 & 810 & 5804 & 303 \\
\hline 808 & 812 & 37500 & 300 \\
\hline 812 & 814 & 29730 & 300 \\
\hline 814 & 850 & 10 & 301 \\
\hline 816 & 818 & 1710 & 302 \\
\hline 816 & 824 & 10210 & 301 \\
\hline 818 & 820 & 48150 & 302 \\
\hline 820 & 822 & 13740 & 302 \\
\hline 824 & 826 & 3030 & 303 \\
\hline 824 & 828 & 840 & 301 \\
\hline 828 & 830 & 20440 & 301 \\
\hline 830 & 854 & 520 & 301 \\
\hline
\end{tabular}




\begin{tabular}{|c|c|c|c|}
832 & 858 & 4900 & 301 \\
\hline 832 & 888 & 0 & XFM-1 \\
\hline 834 & 860 & 2020 & 301 \\
\hline 834 & 842 & 280 & 301 \\
\hline 836 & 840 & 860 & 301 \\
\hline 836 & 862 & 280 & 301 \\
\hline 842 & 844 & 1350 & 301 \\
\hline 844 & 846 & 3640 & 301 \\
\hline 846 & 848 & 530 & 301 \\
\hline 850 & 816 & 310 & 301 \\
\hline 852 & 832 & 10 & 301 \\
\hline 854 & 856 & 23330 & 303 \\
\hline 854 & 852 & 36830 & 301 \\
\hline 858 & 864 & 1620 & 302 \\
\hline 858 & 834 & 5830 & 301 \\
\hline 860 & 836 & 2680 & 301 \\
\hline 862 & 838 & 4860 & 304 \\
\hline 888 & 890 & 10560 & 300 \\
\hline
\end{tabular}

Table 3: Conductor Data

\begin{tabular}{|l|l|l|l|l|l|}
\hline Size & Stranding & Material & $\begin{array}{l}\text { Diameter } \\
\text { (inches) }\end{array}$ & GMR (feet) & $\begin{array}{l}\text { Resistance } \\
\text { (ohm } / \text { mile) }\end{array}$ \\
\hline $1 / 0$ & & ACSR & 0.398 & 0.00446 & 1.12 \\
\hline 2 & $6 / 1$ & ACSR & 0.316 & 0.00418 & 1.69 \\
\hline 4 & $6 / 1$ & ACSR & 0.25 & 0.00437 & 2.57 \\
\hline
\end{tabular}

Table 4: Overhead Lines Spacing

\begin{tabular}{|c|l|}
\hline Spacing ID & \multicolumn{1}{|c|}{ Type } \\
\hline 500 & Three-Phase, 4 wire \\
\hline 505 & Two-Phase, 3 wire \\
\hline 510 & Single-Phase, 2 wire \\
\hline
\end{tabular}

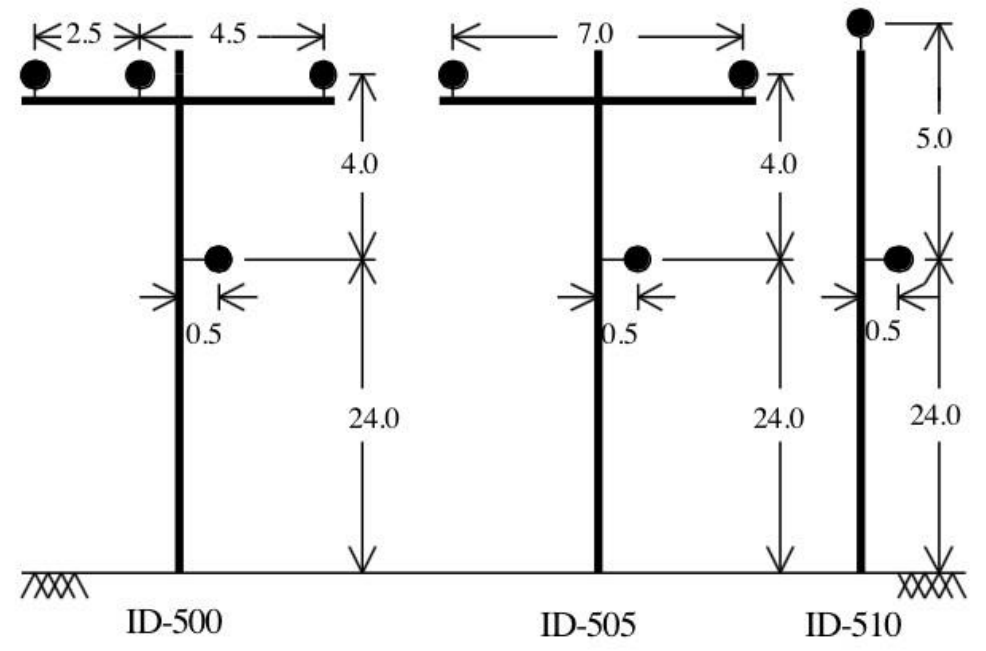

Figure 2: Overhead lines spacing ID 
To calculate the required parameters these equations have been used:

$z_{\Delta}=0.09530+j 0.12134(\ln (1)+7.93402)$

$z=0.09530+j 0.12134\left(\ln \left(\frac{1}{-}\right) \quad 33402\right) \quad$ (3.1 Modified Carson equation)

$\left[z_{\infty}\right]=\left[z_{\infty}\right]-\left[z_{\infty}\right] \cdot\left[z_{n}\right]^{-1} \cdot\left[z_{n}\right.$

$\left[Z_{012}\right]=\left[A_{\diamond}\right]^{-1} \cdot\left[Z_{\infty}\right] \cdot\left[A_{\diamond}\right]$

(3.2 Kron reduction of equations)

Where:

$\begin{array}{lll}1 & 1 & 1\end{array}$

$A_{\diamond}=\left[\begin{array}{lll}1 & a^{2} & a\end{array}\right]$, The operator $\mathrm{a}$ is a vector with magnitude of 1 and angle of 120 degrees

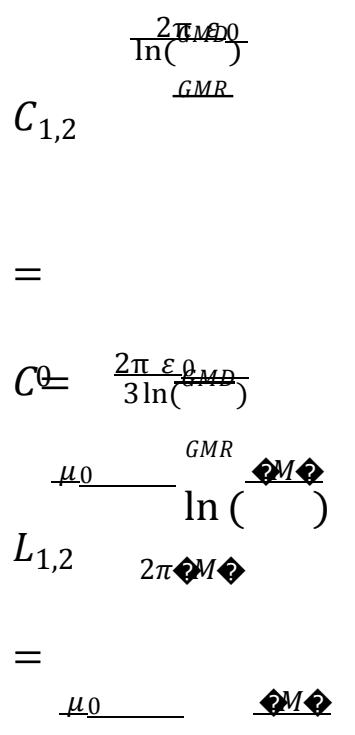

$L_{0}=3 \ln ($ Affter doing the required calculations for each different line, the required transmission line parameters are shown in the table belwo.

Table 5: Three-Phase Transmission Line Model Parameters

\begin{tabular}{|c|c|c|c|c|c|c|}
\hline Config & $\mathrm{R}_{0}(\mathrm{Ohm} / \mathrm{km})$ & $\mathrm{R}_{1}(\mathrm{Ohm} / \mathrm{km})$ & $\mathrm{L}_{0}(\mathrm{mH} / \mathrm{km})$ & $\mathrm{L}_{1}(\mathrm{mH} / \mathrm{km})$ & $\mathrm{C}_{0}(\mathrm{nF} / \mathrm{km})$ & $\mathrm{C}_{1}(\mathrm{nF} / \mathrm{km})$ \\
\hline 300 & 1.08748 & 0.696134 & 4.121 & 1.3736 & 2.7 & 8.1 \\
\hline 301,304 & 1.48378 & 1.18818 & 4.346 & 1.449 & 2.675 & 8.024 \\
\hline
\end{tabular}

Table 6: Single Phase Transmission Line Model Parameters

\begin{tabular}{|c|c|c|c|}
\hline Config & $\mathrm{R}(\mathrm{Ohm} / \mathrm{km})$ & $\mathrm{L}(\mathrm{mH} / \mathrm{km})$ & $\mathrm{C}(\mathrm{nF} / \mathrm{km})$ \\
\hline
\end{tabular}




\begin{tabular}{|c|c|c|c|}
\hline 302,303 & 1.59727 & 3.86 & 4.716 \\
\hline
\end{tabular}




\subsubsection{Modeling and Testing the}

\section{Simulation}

The remaining parts of the Test Feeder were modeled using SIMULINK, and the overall model was tested to ensure the accuracy of the simulation. The model was simulated, and the results were compared with the IEEE 34 Node Test Feeder power results. The simulation was done in Phasor Mode to check the current and voltages along the transmission lines.

After testing the Model, the DGs were connected. Starting with $25 \%$ on node 585 and then another DG at node 584 to reach to $50 \%$ of the power coming from the DG. Finally, a third DG was connected to the node 836 to reach $75 \%$ of power coming from the three DGs. Another testing was done on the model after injecting the power using the DGs. The power losses in the transmission line were reduced as the distance between the power generators and the loads became shorter.

The figure below shows the overall model for the Test Feeder in Simulink with all the DGs connected to the system. This final model is the model used in testing all the proposed algorithms for identifying the fault location. 


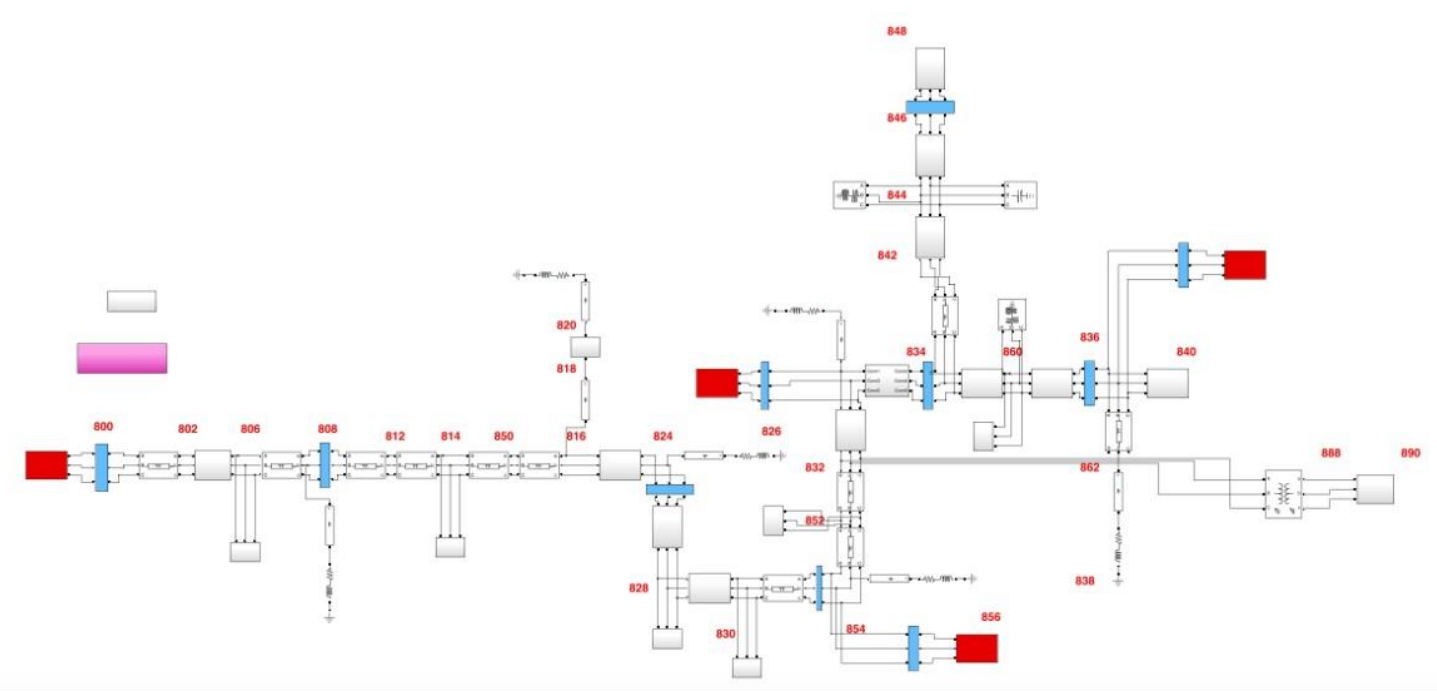

Figure 3: SIMULINK Model of IEEE 34 Node Test Feeder

\subsubsection{Identifying the Zones}

To be able to test the simulated Test Feeder, The Feeder was divided into different zones. Each Zone will start and end with a measurement block. These measurements will be used for the proposed algorithms to detect the faults. The figure below shows the zones in the simulated model. The faults will be in zone 2, and zone 4, and the measurement will be collected from both ends of the zones for further analysis to detect the fault location. The figure below shows the different zones in the final Model 


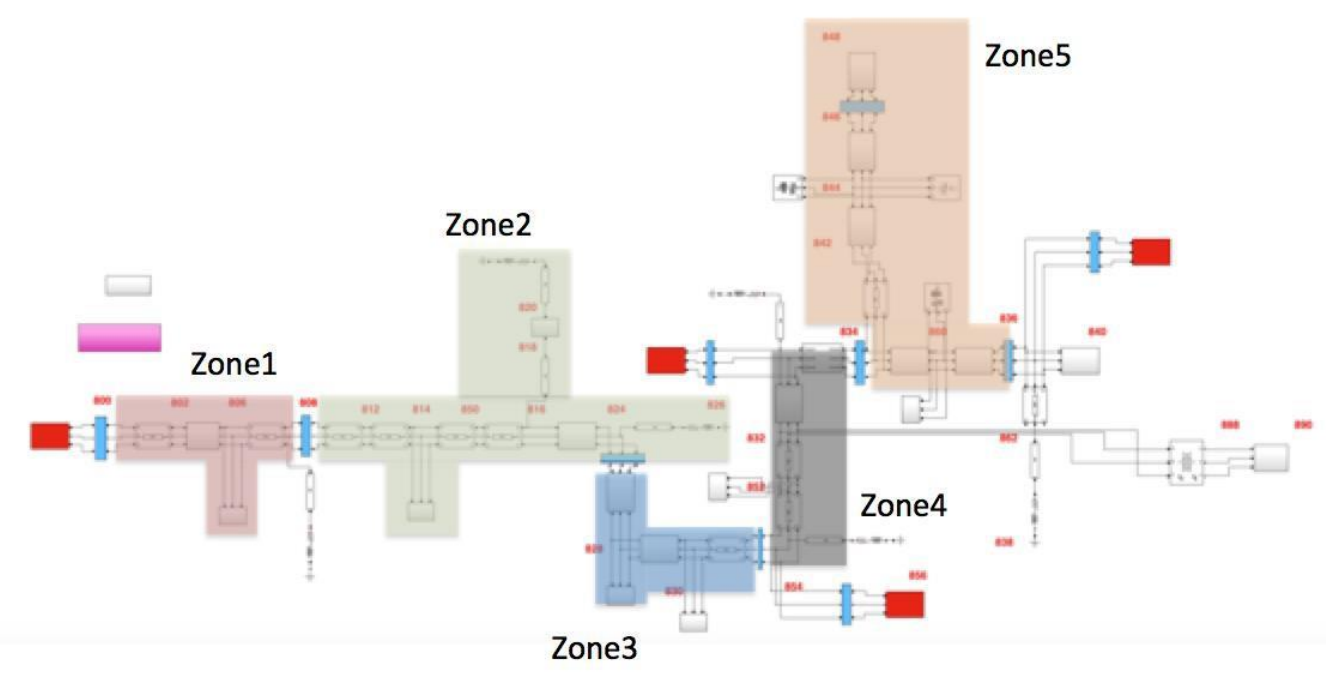

Figure 4: Division of the Zones in the Simulated Model

\subsection{Fault Types Simulated}

The proposed algorithm will be tested for two different kinds of faults, and the result will be collected for further analysis. The faults, which will be tested in the simulation, are:

- Three-phase to ground fault (no resistance, through 10-ohm resistance)

- Line to line fault between phase $A$ and phase $B$

- Single-phase to ground fault

Each type of fault will be simulated in zone 2, and 5 and the measurement will be taken from the measuring block in both ends of each zone. The faults will be programmed to occur during the normal operation of the system in either of the mentioned zones. 


\section{Chapter 4}

\section{Algorithms for Fault Identification}

To test each method for fault location identification, the Change of Current method and the Artificial Neural Network will be simulated separately. The same model that has been discussed in the previous chapter will be used in both with Phasor Mode for the simulator. For each method, a separate SIMULINK model will be generated, and the algorithm should be able to detect the fault location in real time while the system is running.

In this section, the algorithm for each method will be explained. The algorithm will run in real time in the simulation to detect any fault that might occur. As mentioned previously, the tested zones are 2 and 5 so the algorithm will detect if a fault happened in one of the zones. Also, it should be able to identify the fault type.

\subsection{Change of Current}

The change of current method has been widely used for fault identification, and it is considered as one of the most reliable methods. This 
method will be tested while injecting power from the DGs into the power system to provide the power for the loads.

\subsubsection{Change of Current Equations}

Measurements are taken from both ends of each zone. Using Kirchhoff's law, the method will calculate the difference in the current form upstream and downstream of the zone, i.e.

$I_{z} \diamond \quad=\quad I_{z \diamond} \diamond \quad-\quad \quad I_{z} \diamond$ (4.1.1)

Where $I_{z k}$ is the three-phase current for zone $k$, defined as the difference between the current entering the zone and the current leaving the zone. I I is calculated in real time while the PS is in normal operations. To determine whether there is a fault in the zone $\mathrm{k}$ or not, the system will calculate the percentage change in the zone using the equations given below.

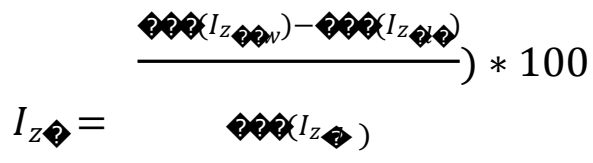

(

Where $I_{z F}$ is the fault percentage change in current. The system will compare this value to a pre-set threshold to determine if there is a fault in zone k or not.

The previously described calculation will be done in both of the zones 2 and 5 to find the location of the fault and after the location is determined, the system will display the corresponding number of the faulted zone. 


\subsubsection{Change of Current Algorithm}

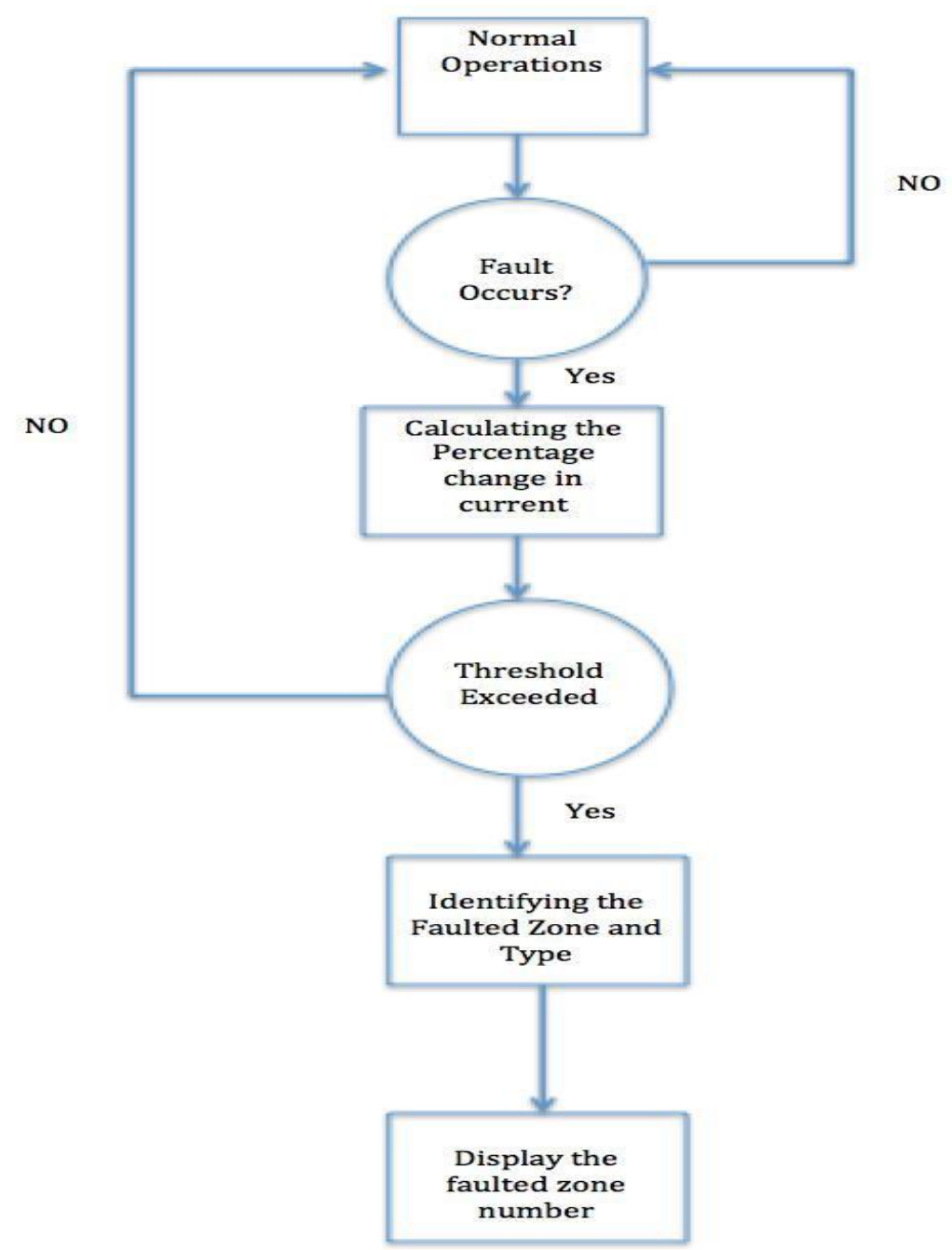

Figure 5: Change of Current Algorithm Flow Chart

Figure 5 shows the change of current algorithm flow chart. During the normal operation recording, the data from the measurement blocks continuously monitors the current. The system has access to measurements from both tested zones and can calculate the percentage change in both the zones. 
The following algorithm specifies the steps to identify the fault location

1. The system will calculate current for each zone during the normal operation.

2. When the fault occurs, the system will calculate the new current of each zone.

3. The percentage change of current will be calculated using both the new and the old current values.

4. The percentage change will be compared to the threshold value. If it didn't exceed the threshold, the system would go back to normal operation otherwise it would continue to the next step.

5. If the threshold is exceeded, this will indicate that there is a fault in the zone where the threshold was exceeded. The system will detect in which phase in the faulted zone the threshold was exceeded and by looking to each phase current change the system will be able to specify the fault type.

6. The system will send a number to the display corresponding to the faulted zone identified by the system. 


\subsection{Symmetrical Components}

Symmetrical Components are used to describe the behavior of PDS and any change in these components can be calculated and used to identify the location of faults in the system. Symmetrical components can be used in a balanced and unbalanced PS. This method can be used to identify the fault location and test the method with different amount of power injected from DGs into the power system,

\subsubsection{Symmetrical Components}

\section{Equations}

Zone currents are determined to find Positive, Negative, and zero sequence currents according to the following formulas.

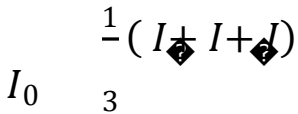

$$
\begin{aligned}
& =1_{\left(I+a * I+a^{2}{ }^{3}\right.} \\
& \left.I_{1} \quad * I_{8}\right) \\
& \begin{array}{ll}
= & \frac{1}{3}\left(I_{6}+a^{2}\right. \\
I_{2} & \left.* I_{\diamond}+a * I_{\diamond}\right)
\end{array} \\
& =
\end{aligned}
$$

Where $I_{a}$ is the zone current of phase $A, I_{b}$ is the zone current of phase $B, I_{c}$ is the zone current of phase $\mathrm{C}$ and the operator $\mathrm{a}$ is a vector with magnitude of 1 and angle of $120^{\circ}$. 
After calculating the symmetrical current, the difference change between the old symmetrical current (No-Fault) and the new symmetrical current (with Fault in the PS) will be calculated with the use of percentage change of the result to identify the location and type of the fault.

\subsubsection{Symmetrical Components}

\section{Algorithm}

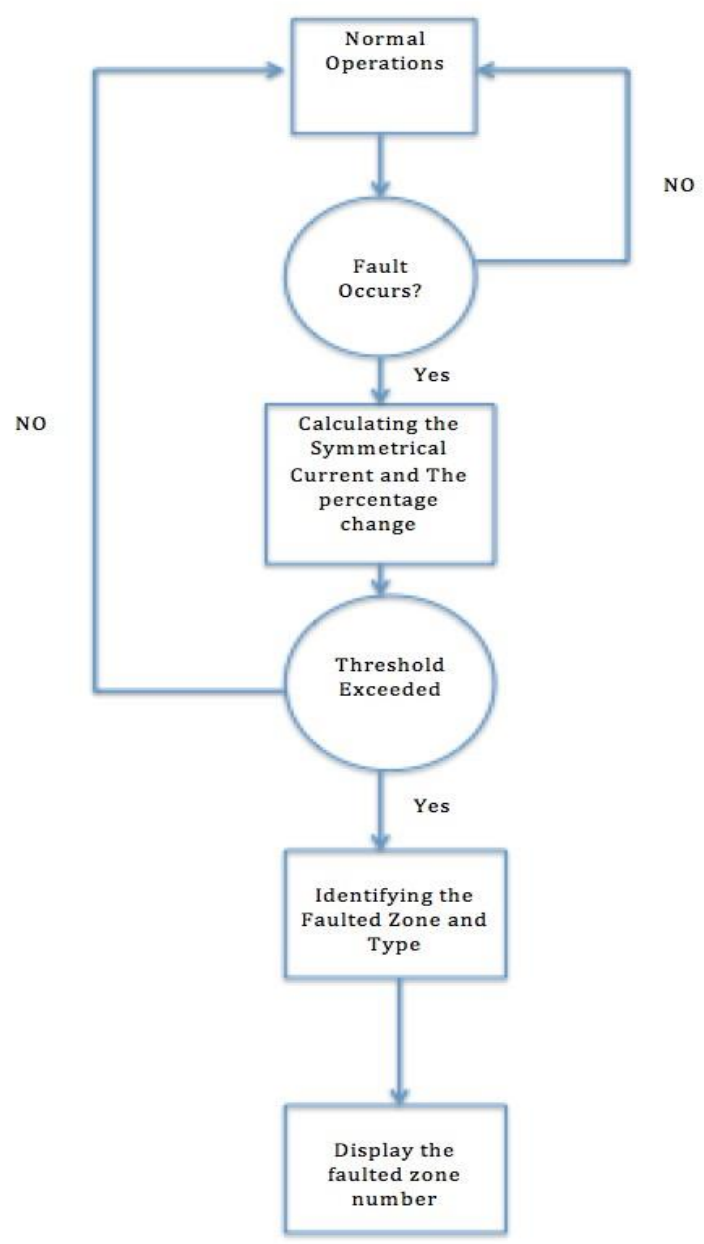

Figure 6: Symmetrical Component Method Flow Chart 
Figure 6 shows the flow chart of the symmetrical component method, and it is similar to the change of current method with a minor difference. The following steps will describe how the method works:

1. The system will calculate current for each zone during the normal operation.

2. When the fault occurs, the system will calculate the new current of each zone.

3. The symmetrical current and percentage change of current will be calculated using both the new and the old current values.

4. The percentage change will be compared to the threshold value. If it did not exceed the threshold, the system would go back to normal operation otherwise it will continue to the next step.

5. If the threshold is exceeded, this will indicate that there is a fault in the zone where the threshold was exceeded. The system will identify the type of the fault by knowing which component has changed (Positive, Negative, and Zero).

6. The system will send a number to the display corresponding to the faulted zone identified by the system. 


\subsection{Artificial Neural Network}

Artificial Neural Network (ANN) is one of the best Artificial intelligence approaches that can be used for fault location identification. All of the artificial intelligence (AI) approaches need a previous knowledge data from the system to train them and get the required results. The data is collected before implementing ANN.

ANN can be considered as a black box where current data from all the zones is the input. After doing the calculation in multiple hidden layers, the output of the box will display the number of the faulted zone.

To get the best result from the ANN, a design is needed to separate networks for each scenario of DGs and identify the fault location and the fault type. Four different networks are needed for:

1. No power injected by the DGs

2. $25 \%$ of power system load supplied by DGs

3. $50 \%$ of power system load supplied by DGs

4. $75 \%$ of power system load supplied by DGs 


\subsubsection{Structure of ANN}

The following structure is used for designing each network as shown in figure 6 below.

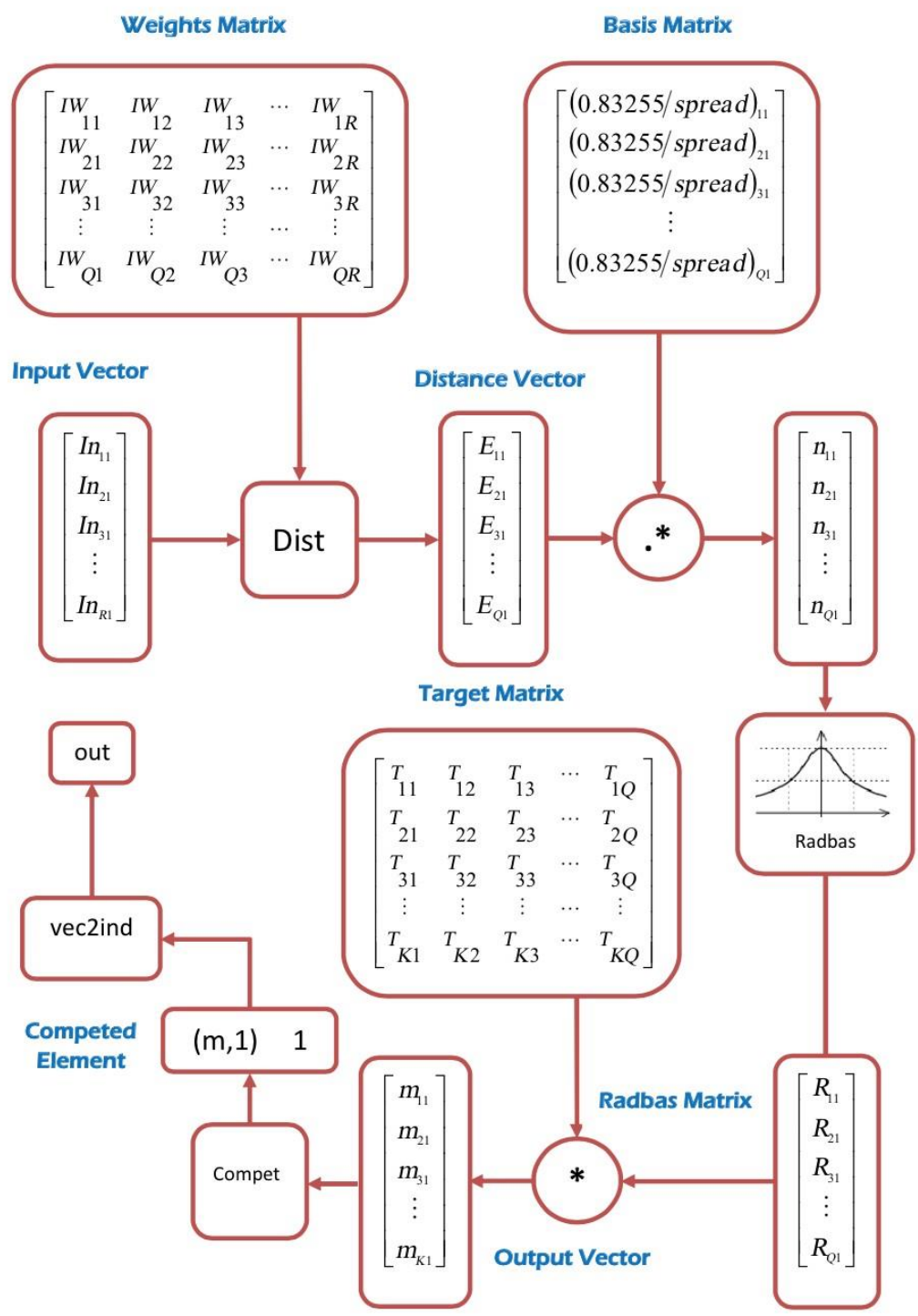

Fiigure 6: Structure of ANN 
Where the input vector is the current data from the system, the weights Matrix is the training data that was obtained before designing the system (which will be described in the next section), the Basis Matrix is automatically adjusted during the training to get the best result possible and the Target Matrix is a customized Matrix that can assign different numbers for each case to identify the faults location.

\subsubsection{Training and Target Data for}

\section{ANN}

The following data was recorded in a matrix form to train the network:

- Training Data1: $\quad$ Current data with no DG and no Faults, Fault in zone 2 and Fault in zone 5

- Training Data2: $\quad$ Current data with $25 \%$ of power load supplied by DG and no Faults, Fault in zone 2 and Fault in zone 5

- Training Data3: $\quad$ Current data with $50 \%$ of power load supplied by DG and no Faults, Fault in zone 2 and Fault in zone 5

- Training Data4: Current data with $75 \%$ of power load supplied by DG and no Faults, Fault in zone 2 and Fault in zone 5 
The Target matrix was set to show the following numbers for the each case as shown below.

- No Fault: output=0

- Three phase fault at zone 2: output=10

- Line to line fault at zone 2: output=20

- Three phase fault at zone 5: output=30

- Line to line fault at zone 5: output=40

The output numbers were set in a way to ensure the best possible result from the Network. If the difference between the output numbers is small, the error in the ANN will be greater.

\subsubsection{Training ANN}

Training the network can be repeated until the best outputs have been achieved. The network will test itself and stop the training when one of the specified limits is reached or when the validation and the error stop decaying. The error was set to be $1 \mathrm{e}-7$ to ensure an accurate network, and the network was trained for at least 1000 iterations. The figure below shows the training performance of one of the networks used in the system. 


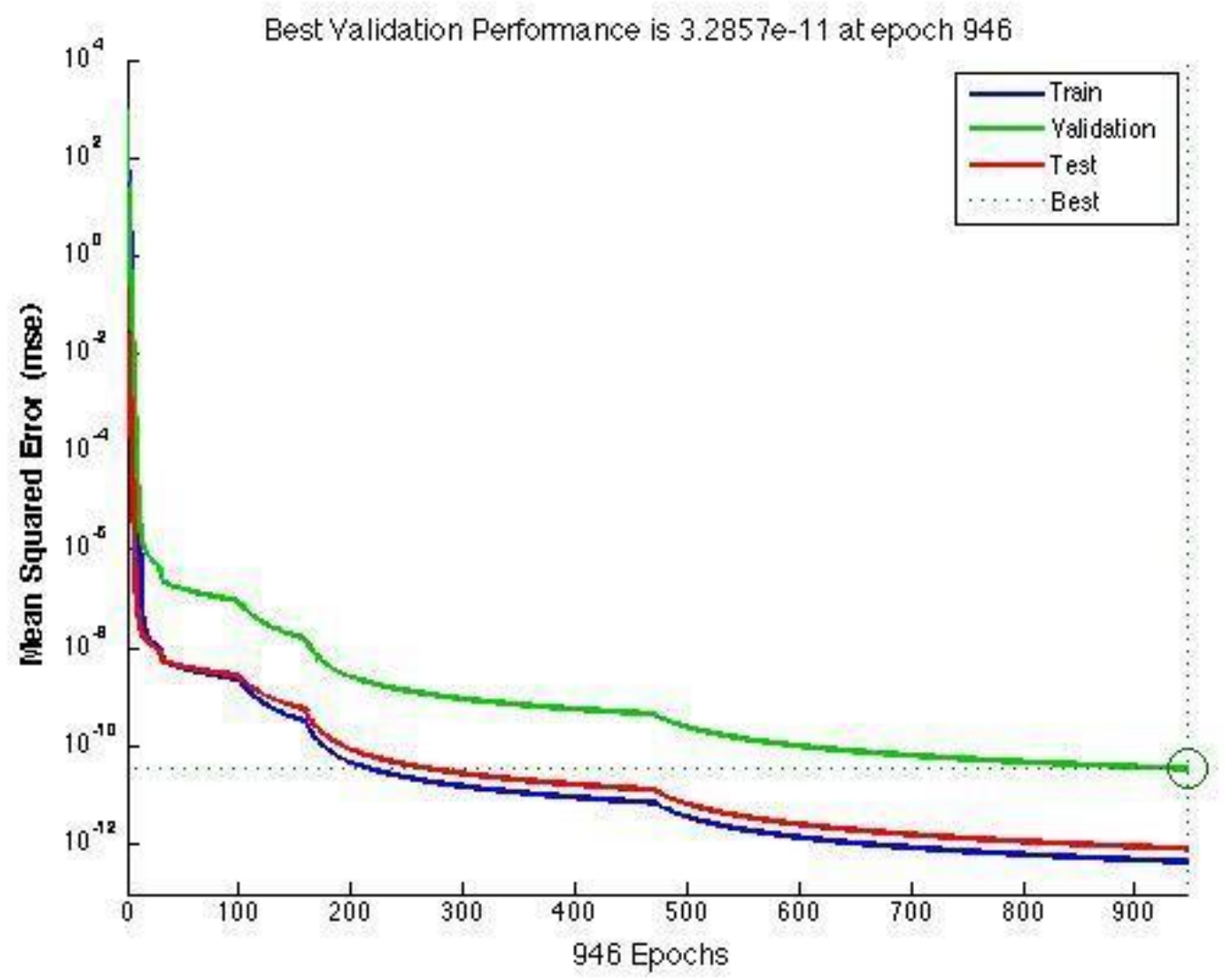

Figure 7: ANN Training Performance 


\section{Chapter 5}

\section{Testing and Results}

In this chapter, the system was tested, and the faults were introduced in zone 2 and zone 5 . The results will be gathered and analyzed to be used for each previously proposed method to compare between the methods and find the advantages/disadvantages of each method. The data will be gathered for each case of load power supplied by DGs (No DG, 25\% DG, 50\% DG and 75\% DG).

\subsection{Testing the System with No}

\section{Faults}

The figure below shows the simulated system with the measurement's locations and labels for each location. The measurement's blocks are colored in light blue. 


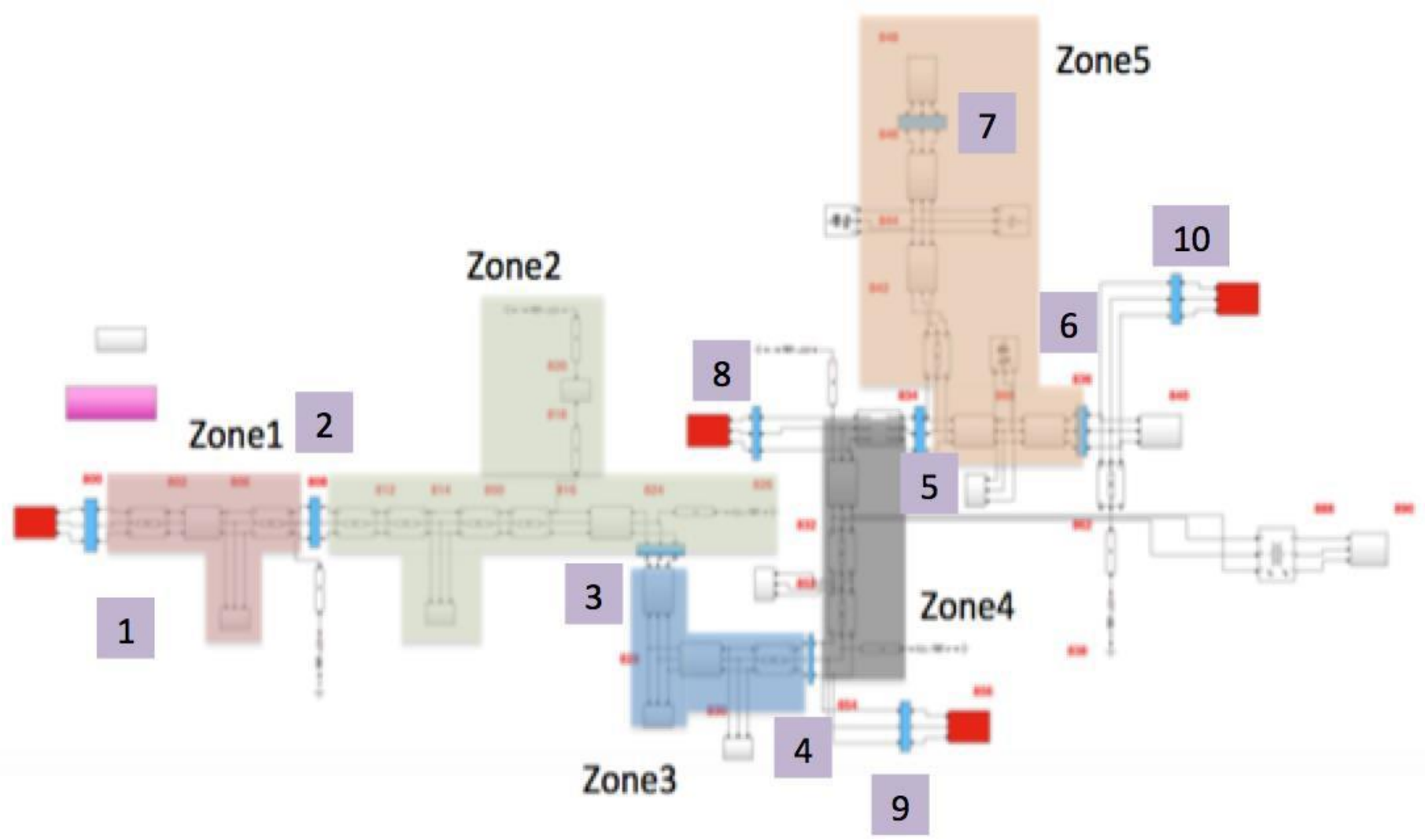

Figure 7: Measurements block location and label

Where the numbers are represented in MATLAB as:

1. I1s, V1s

2. $\mid 1 \mathrm{e}, \mathrm{V} 1 \mathrm{e}$

3. $12 \mathrm{e}, \mathrm{V} 2 \mathrm{e}$

4. $13 e, V 3 e$

5. $14 \mathrm{~s}, \mathrm{~V} 4 \mathrm{~s}$

6. $15 \mathrm{e}, \mathrm{V} 5 \mathrm{e}$

7. $14 \mathrm{e}, \mathrm{V} 4 \mathrm{e}$

8. IG2, VG2 


\section{IG3, VG3}

\section{IG4, VG4}

The following tables show the result for the tested system with No Faults for each case of load power supplied by the DGs.

Table 7: Voltage and Current for PDS with no DG and no faults

\begin{tabular}{|c|c|}
\hline \multicolumn{2}{|c|}{ No DG, No Fault } \\
\hline Voltage & Current \\
\hline $1: \mathrm{V}, \mathrm{A}: \mathrm{G} 2 \mathrm{I}^{\prime}=20412.41 \mathrm{~V}$ & $31: \mathrm{I}, \mathrm{A}: \mathrm{G} 2{ }^{\prime}=0.00 \mathrm{~A}$ \\
\hline $2: \mathrm{V}, \mathrm{B}: \mathrm{G} 2 \mathrm{I}^{\prime}=20412.41 \mathrm{~V}$ & $32: \mathrm{I}, \mathrm{A}: \mathrm{G} 3{ }^{\prime}=0.00 \mathrm{~A}$ \\
\hline 3: V, C: G2 ' = 20412.41 V & $33: \mathrm{I}, \mathrm{A}: \mathrm{G} 4 \mathrm{I}^{\prime}=0.00 \mathrm{~A}$ \\
\hline $4: \mathrm{V}, \mathrm{A}: \mathrm{G} 3 \mathrm{~S}^{\prime}=20412.41 \mathrm{~V} 0.00^{\circ}$ & $34: \mathrm{I}, \mathrm{A}: 11 \mathrm{e}^{\prime}=56.82 \mathrm{~A}-30.88^{\circ}$ \\
\hline $5: \mathrm{V}, \mathrm{B}: \mathrm{G} 3 \mathrm{~S}^{\prime}=20412.41 \mathrm{~V}-120.00^{\circ}$ & $35:$ I, A: $11 \mathrm{~s}^{\prime}=56.49 \mathrm{~A}-30.27^{\circ}$ \\
\hline $6: \mathrm{V}, \mathrm{C}: \mathrm{G} 3{ }^{\prime}=20412.41 \mathrm{~V} 120.00^{\circ}$ & $36: \mathrm{I}, \mathrm{A}: 12 \mathrm{e}^{\prime}=52.18 \mathrm{~A}-33.13^{\circ}$ \\
\hline $7: \mathrm{V}, \mathrm{A}: \mathrm{G} 4{ }^{\prime}=20412.41 \mathrm{~V} 0.00^{\circ}$ & $37: \mathrm{I}, \mathrm{A}: 13 \mathrm{e}^{\prime}=52.03 \mathrm{~A}-33.51^{\circ}$ \\
\hline $8: \mathrm{V}, \mathrm{B}: \mathrm{G} 4 \mathrm{I}^{\prime}=20412.41 \mathrm{~V}-120.00^{\circ}$ & $38: I, A: 14 e^{\prime}=3.41$ A $75.59^{\circ}$ \\
\hline $9: \mathrm{V}, \mathrm{C}: \mathrm{G} 4 \mathrm{I}^{\prime}=20412.41 \mathrm{~V} 120.00^{\circ}$ & $39: I, A: 14 s^{\prime}=9.90 \mathrm{~A}-10.18^{\circ}$ \\
\hline $10: \mathrm{V}, \mathrm{A}: 11 \mathrm{e} \mathrm{I}^{\prime}=19840.99 \mathrm{~V}-0.25^{\circ}$ & $40: \mathrm{I}, \mathrm{A}: 15 \mathrm{e}^{\prime}=0.78 \mathrm{~A}-35.51^{\circ}$ \\
\hline $11: \mathrm{V}, \mathrm{B}: \mathrm{I1 \textrm {e }} \mathrm{\prime}^{\prime}=19968.79 \mathrm{~V}$ & $41: \mathrm{I}, \mathrm{B}: \mathrm{G} 2 \mathrm{\prime}^{\prime}=0.00 \mathrm{~A}$ \\
\hline 12: V, C: I1e ' = 19907.64 V & $42: \mathrm{I}, \mathrm{C}: \mathrm{G} 2 \mathrm{I}^{\prime}=0.00 \mathrm{~A}$ \\
\hline $13: \mathrm{V}, \mathrm{A}: \mathrm{I1} \mathrm{s}^{\prime}=20407.49 \mathrm{~V}$ & 43: I, B: G3 ' = $0.00 \mathrm{~A}$ \\
\hline $14: \mathrm{V}, \mathrm{B}: \mathrm{I1 \textrm {s } ^ { \prime }}=20408.29 \mathrm{~V}$ & $44:$ I, C: G3 ' $=0.00 \mathrm{~A}$ \\
\hline 15: V, C: I1s ' = $20407.96 \mathrm{~V}$ & $45:$ I, B: G4 ' $=0.00 \mathrm{~A}$ \\
\hline $16: \mathrm{V}, \mathrm{A}: \mathrm{I2 \textrm {e }} \mathrm{\prime}^{\prime}=18471.48 \mathrm{~V}$ & $46: \mathrm{I}, \mathrm{C}: \mathrm{G} 4{ }^{\prime}=0.00 \mathrm{~A}$ \\
\hline $17: \mathrm{V}, \mathrm{B}: \mathrm{I2 \textrm {e } ^ { \prime }}=18884.74 \mathrm{~V}-121.01^{\circ}$ & $47: I, B: I 1 e^{\prime}=48.61$ A $-148.77^{\circ}$ \\
\hline $18: \mathrm{V}, \mathrm{C}: 12 \mathrm{e}^{\prime}=18657.41 \mathrm{~V} 119.40^{\circ}$ & $48: \mathrm{I}, \mathrm{C}: 11 \mathrm{e}^{\prime}=51.45 \mathrm{~A} 89.84^{\circ}$ \\
\hline 19: V, A: I3e ' = $17818.95 \mathrm{~V}-2.02^{\circ}$ & $49:$ I, B: I1s ' $=49.96 \mathrm{~A}-147.93^{\circ}$ \\
\hline $20: \mathrm{V}, \mathrm{B}: 13 \mathrm{e} \mathrm{I}^{\prime}=18326.81 \mathrm{~V}-121.81^{\circ}$ & $50:$ I, C: $11 \mathrm{~s}^{\prime}=52.07 \mathrm{~A} 90.52^{\circ}$ \\
\hline $21: \mathrm{V}, \mathrm{C}: 13 \mathrm{e} \mathrm{e}^{\prime}=17992.76 \mathrm{~V} 118.58^{\circ}$ & $51: \mathrm{I}, \mathrm{B}: 12 \mathrm{e}^{\prime}=47.77 \mathrm{~A}-150.35^{\circ}$ \\
\hline $22: \mathrm{V}, \mathrm{A}: 14 \mathrm{e}^{\prime}=15591.03 \mathrm{~V}-5.94^{\circ}$ & $52: \mathrm{I}, \mathrm{C}: 12 \mathrm{e}^{\prime}=52.14 \mathrm{~A} 88.50^{\circ}$ \\
\hline $23: \mathrm{V}, \mathrm{B}: 14 \mathrm{e}^{\prime}=16490.69 \mathrm{~V}-124.93^{\circ}$ & $53:$ I, B: $13 \mathrm{e}^{\prime}=47.38 \mathrm{~A}-150.80^{\circ}$ \\
\hline $24: \mathrm{V}, \mathrm{C}: 14 \mathrm{e}^{\prime}=15730.89 \mathrm{~V} 115.29^{\circ}$ & $54:$ I, C: $13 e^{\prime}=51.40$ A $87.99^{\circ}$ \\
\hline $25: \mathrm{V}, \mathrm{A}: 14 \mathrm{~s}^{\prime}=15591.06 \mathrm{~V}-5.89^{\circ}$ & $55:$ I, B: $14 \mathrm{e}^{\prime}=3.47 \mathrm{~A}-54.16^{\circ}$ \\
\hline $26: \mathrm{V}, \mathrm{B}: 14 \mathrm{~s}^{\prime}=16480.23 \mathrm{~V}-124.89^{\circ}$ & $56: \mathrm{I}, \mathrm{C}: 14 \mathrm{e}^{\prime}=3.45 \mathrm{~A}-163.18^{\circ}$ \\
\hline $27: \mathrm{V}, \mathrm{C}: 14 \mathrm{~s}^{\prime}=15727.45 \mathrm{~V} 115.32^{\circ}$ & $57:$ I, B: $14 s^{\prime}=6.27$ A $-83.79^{\circ}$ \\
\hline $28: \mathrm{V}, \mathrm{A}: 15 \mathrm{e}^{\prime}=15586.47 \mathrm{~V}-5.89^{\circ}$ & $58: \mathrm{I}, \mathrm{C}: 14 \mathrm{~s}^{\prime}=9.07 \mathrm{~A} 119.28^{\circ}$ \\
\hline $29: \mathrm{V}, \mathrm{B}: 15 \mathrm{e}^{\prime}=16473.27 \mathrm{~V}-124.90^{\circ}$ & $59: \mathrm{I}, \mathrm{B}: 15 \mathrm{e}^{\prime}=1.76 \mathrm{~A}-151.85^{\circ}$ \\
\hline $30: \mathrm{V}, \mathrm{C}: 15 \mathrm{e}^{\prime}=15722.79 \mathrm{~V} 115.31^{\circ}$ & $60:$ I, C: $15 \mathrm{e}^{\prime}=0.28 \mathrm{~A} 80.16^{\circ}$ \\
\hline
\end{tabular}


Table 8: Voltage and Current for PDS with 25\% DG and no faults

\begin{tabular}{|c|c|}
\hline \multicolumn{2}{|c|}{ No DG, No Fault } \\
\hline Voltage & Current \\
\hline 1: V, A: G2 ' = $17023.20 \mathrm{~V}-5.94^{\circ}$ & $31: I, A: G 2^{\prime}=18.53 \mathrm{~A}-55.04^{\circ}$ \\
\hline $2: \mathrm{V}, \mathrm{B}: \mathrm{G} 2^{\prime}=17583.29 \mathrm{~V}-125.08^{\circ}$ & 32: I, A: G3 ' = $0.00 \mathrm{~A}$ \\
\hline 3: V, C: G2 ' = 17101.00 V 114.59º & 33: I, A: G4 ' = $0.00 \mathrm{~A}$ \\
\hline 4: V, A: G3 ' = 20412.41 V & 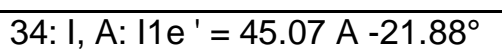 \\
\hline 5: V, B: G3 ' = $20412.41 \mathrm{~V}$ & 35: I, A: I1s ' = 44.84 A $-21.05^{\circ}$ \\
\hline 6: V, C: G3 ' = 20412.41 V & $36: I, A: I 2 e^{\prime}=40.03$ A $-23.69^{\circ}$ \\
\hline $7: \mathrm{V}, \mathrm{A}: \mathrm{G} 4 \mathrm{I}^{\prime}=20412.41 \mathrm{~V}$ & $37: I, A: I 3 e^{\prime}=39.83$ A $-24.16^{\circ}$ \\
\hline $8: \mathrm{V}, \mathrm{B}: \mathrm{G} 4 \mathrm{I}^{\prime}=20412.41 \mathrm{~V}$ & $38: \mathrm{I}, \mathrm{A}: 14 \mathrm{e}^{\prime}=3.72 \mathrm{~A} 75.40^{\circ}$ \\
\hline 9: V, C: G4 ' = 20412.41 V & 39: I, A: I4s ' = 10.79 A - $10.37^{\circ}$ \\
\hline 10: V, A: I1e ' = 19973.91 V -0.39º & $40: I, A: 15 e^{\prime}=0.85 \mathrm{~A}-35.70^{\circ}$ \\
\hline $11: \mathrm{V}, \mathrm{B}: \mathrm{I1} \mathrm{e}^{\prime}=20076.96 \mathrm{~V}-120.36^{\circ}$ & 41: I, B: G2 ' = $15.63 \mathrm{~A}-173.62^{\circ}$ \\
\hline $12: \mathrm{V}, \mathrm{C}: \mathrm{I1 \textrm {e } ^ { \prime }}=20031.73 \mathrm{~V} 119.73^{\circ}$ & 42: I, C: G2 ' = 17.83 A $63.60^{\circ}$ \\
\hline $13: \mathrm{V}, \mathrm{A}: \mathrm{I} \mathrm{s}^{\prime}=20409.35 \mathrm{~V}-0.02^{\circ}$ & 43: I, B: G3 ' = $0.00 \mathrm{~A}$ \\
\hline $14: \mathrm{V}, \mathrm{B}: \mathrm{I1s} \mathrm{s}^{\prime}=20409.91 \mathrm{~V}-120.01^{\circ}$ & 44: I, C: G3 ' = $0.00 \mathrm{~A}$ \\
\hline $15: \mathrm{V}, \mathrm{C}: \mathrm{I1s} \mathrm{s}^{\prime}=20409.76 \mathrm{~V} 119.99^{\circ}$ & 45: I, B: G4 ' = $0.00 \mathrm{~A}$ \\
\hline $16: V, A: I 2 e^{\prime}=18944.16 \mathrm{~V}-1.52^{\circ}$ & 46: I, C: G4 ' $=0.00 \mathrm{~A}$ \\
\hline $17: \mathrm{V}, \mathrm{B}: \mathrm{I} 2 \mathrm{e}^{\prime}=19265.93 \mathrm{~V}-121.37^{\circ}$ & $47: I, B: I 1 e^{\prime}=38.19$ A -139.38 \\
\hline $18: \mathrm{V}, \mathrm{C}: \mathrm{I2e} \mathrm{e}^{\prime}=19100.00 \mathrm{~V} 118.84^{\circ}$ & 48: I, C: I1e ' = 40.26 A 99.97º \\
\hline 19: V, A: I3e ' = $18493.20 \mathrm{~V}-2.45^{\circ}$ & $49:$ I, B: I1s ' = $39.63 \mathrm{~A}-138.65^{\circ}$ \\
\hline $20: V, B: I 3 e^{\prime}=18865.77 \mathrm{~V}-122.17^{\circ}$ & $50:$ I, C: I1s ' $=40.98$ A $100.67^{\circ}$ \\
\hline $21:$ V, C: I3e ' = 18627.69 V 117.93 & $51: I, B: I 2 e^{\prime}=37.11 \mathrm{~A}-141.17^{\circ}$ \\
\hline $22: \mathrm{V}, \mathrm{A}: 14 \mathrm{e}^{\prime}=16998.63 \mathrm{~V}-6.13^{\circ}$ & $52:$ I, C: $12 e^{\prime}=40.73$ A $98.07^{\circ}$ \\
\hline $23: \mathrm{V}, \mathrm{B}: 14 \mathrm{e}^{\prime}=17606.76 \mathrm{~V}-125.18^{\circ}$ & $53:$ I, B: I3e ' = $36.65 \mathrm{~A}-141.65^{\circ}$ \\
\hline $24: \mathrm{V}, \mathrm{C}: 14 \mathrm{e}^{\prime}=17074.20 \mathrm{~V} 114.47^{\circ}$ & 54: I, C: I3e ' = 39.90 A $97.61^{\circ}$ \\
\hline 25: V, A: I4s ' = 16998.45 V -6.08 & $55:$ I, B: $14 e^{\prime}=3.71 \mathrm{~A}-54.41^{\circ}$ \\
\hline $26: \mathrm{V}, \mathrm{B}: 14 \mathrm{~s}^{\prime}=17595.68 \mathrm{~V}-125.14^{\circ}$ & $56:$ I, C: $14 e^{\prime}=3.74$ A - $164.00^{\circ}$ \\
\hline $27:$ V, C: $14 s^{\prime}=17070.55 \mathrm{~V} 114.50^{\circ}$ & 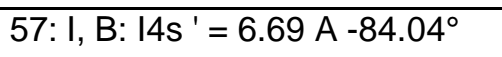 \\
\hline 28: V, A: I5e ' = 16993.47 V -6.08 & 58: I, C: $14 s^{\prime}=9.84$ A $118.46^{\circ}$ \\
\hline $29: \mathrm{V}, \mathrm{B}: 15 \mathrm{e}^{\prime}=17588.31 \mathrm{~V}-125.15^{\circ}$ & 59: I, B: I5e ' = $1.88 \mathrm{~A}-152.10^{\circ}$ \\
\hline $30:$ V, C: $15 e^{\prime}=17065.39 \mathrm{~V} 114.49^{\circ}$ & $60:$ I, C: $15 \mathrm{e}^{\prime}=0.30 \mathrm{~A} 79.33^{\circ}$ \\
\hline
\end{tabular}


Table 9: Voltage and Current for PDS with 50\% DG and no faults

\begin{tabular}{|c|c|}
\hline \multicolumn{2}{|c|}{ No DG, No Fault } \\
\hline Voltage & Current \\
\hline 1: V, A: G2 ' = 17583.68 V -5.70 & $31: \mathrm{I}, \mathrm{A}: \mathrm{G} 2^{\prime}=16.15 \mathrm{~A}-50.96^{\circ}$ \\
\hline $2: \mathrm{V}, \mathrm{B}: \mathrm{G} 2{ }^{\prime}=18048.86 \mathrm{~V}-124.86^{\circ}$ & 32: I, A: G3 ' = 19.93 A $-48.20^{\circ}$ \\
\hline 3: V, C: G2 ' = 17626.43 V $114.72^{\circ}$ & 33: I, A: G4 ' = $0.00 \mathrm{~A}$ \\
\hline 4: V, A: G3 ' = 19264.21 V -2.31 & $34:$ I, A: I1e ' = 31.27 A $-10.10^{\circ}$ \\
\hline $5: \mathrm{V}, \mathrm{B}: \mathrm{G3}{ }^{\prime}=19465.13 \mathrm{~V}-122.05^{\circ}$ & $35: I, A: I 1 s^{\prime}=31.18 \mathrm{~A}-8.84^{\circ}$ \\
\hline 6: V, C: G3 ' = 19344.41 V $117.85^{\circ}$ & $36: I, A: I 2 e^{\prime}=25.94$ A $-10.52^{\circ}$ \\
\hline 7: V, A: G4 ' = 20412.41 V & $37: \mathrm{I}, \mathrm{A}: \mathrm{I3e} \mathrm{e}^{\prime}=25.65 \mathrm{~A}-11.14^{\circ}$ \\
\hline 8: V, B: G4 ' = $20412.41 \mathrm{~V}$ & 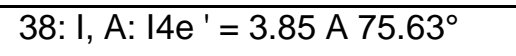 \\
\hline 9: V, C: G4 ' = 20412.41 V & 39: I, A: I4s ' = 11.15 A -10.14 \\
\hline $10: \mathrm{V}, \mathrm{A}: \mathrm{I} 1 \mathrm{e}^{\prime}=20132.48 \mathrm{~V}-0.44^{\circ}$ & $40: I, A: I 5 e^{\prime}=0.88$ A $-35.47^{\circ}$ \\
\hline $11: \mathrm{V}, \mathrm{B}: \mathrm{I1} \mathrm{e}^{\prime}=20202.58 \mathrm{~V}-120.39^{\circ}$ & 41: I, B: G2 ' = 13.64 A -169.67º \\
\hline $12: \mathrm{V}, \mathrm{C}: \mid 1 \mathrm{e}^{\prime}=20177.88 \mathrm{~V} 119.65^{\circ}$ & 42: I, C: G2 ' = 15.63 A $67.69^{\circ}$ \\
\hline $13: \mathrm{V}, \mathrm{A}: \mathrm{I1 \textrm {s } ^ { \prime }}=20411.14 \mathrm{~V}-0.01^{\circ}$ & 43: I, B: G3 ' = $16.92 \mathrm{~A}-165.85^{\circ}$ \\
\hline $14: \mathrm{V}, \mathrm{B}: \mathrm{I1s} \mathrm{S}^{\prime}=20411.41 \mathrm{~V}-120.01^{\circ}$ & 44: I, C: G3 ' = 18.56 A $71.97^{\circ}$ \\
\hline $15:$ V, C: I1s ' = 20411.44 V $119.99^{\circ}$ & 45: I, B: G4 ' = $0.00 \mathrm{~A}$ \\
\hline 16: V, A: I2e ' = $19497.42 \mathrm{~V}-1.57^{\circ}$ & 46: I, C: G4 ' $=0.00 \mathrm{~A}$ \\
\hline $17: \mathrm{V}, \mathrm{B}: \mathrm{I} 2 \mathrm{e}^{\prime}=19700.20 \mathrm{~V}-121.39^{\circ}$ & $47:$ I, B: I1e ' = $26.24 \mathrm{~A}-127.14^{\circ}$ \\
\hline 18: V, C: I2e ' = $19611.93 \mathrm{~V} 118.66^{\circ}$ & $48:$ I, C: I1e ' = 27.48 A $113.20^{\circ}$ \\
\hline $19: \mathrm{V}, \mathrm{A}: \mathrm{I3e} \mathrm{e}^{\prime}=19264.21 \mathrm{~V}-2.31^{\circ}$ & 49: I, B: I1s ' = 27.76 A -126.76 \\
\hline $20: \mathrm{V}, \mathrm{B}: \mathrm{I3e} \mathrm{e}^{\prime}=19465.13 \mathrm{~V}-122.05^{\circ}$ & $50: I^{\prime}, \mathrm{C}:$ IIs $^{\prime}=28.29 \mathrm{~A} 113.86^{\circ}$ \\
\hline $21: \mathrm{V}, \mathrm{C}: \mid 3 \mathrm{e}^{\prime}=19344.41 \mathrm{~V} 117.85^{\circ}$ & $51:$ I, B: I2e ' = 24.91 A -129.25 \\
\hline $22: \mathrm{V}, \mathrm{A}: 14 \mathrm{e}^{\prime}=17558.41 \mathrm{~V}-5.89^{\circ}$ & $52:$ I, C: I2e ' = 27.65 A $110.23^{\circ}$ \\
\hline 23: V, B: $14 \mathrm{e}^{\prime}=18073.01 \mathrm{~V}-124.96^{\circ}$ & $53:$ I, B: I3e ' = $24.38 \mathrm{~A}-129.74^{\circ}$ \\
\hline $24: \mathrm{V}, \mathrm{C}: 14 \mathrm{e}^{\prime}=17598.68 \mathrm{~V} 114.61^{\circ}$ & $54:$ I, C: I3e ' = 26.73 A $109.92^{\circ}$ \\
\hline $25: \mathrm{V}, \mathrm{A}: 14 \mathrm{~s}^{\prime}=17558.17 \mathrm{~V}-5.84^{\circ}$ & $55:$ I, B: $14 e^{\prime}=3.81$ A $-54.19^{\circ}$ \\
\hline $26: \mathrm{V}, \mathrm{B}: \mathrm{I4 \textrm {s } ^ { \prime }}=18061.65 \mathrm{~V}-124.92^{\circ}$ & $56:$ I, C: $14 e^{\prime}=3.85 \mathrm{~A}-163.87^{\circ}$ \\
\hline $27: \mathrm{V}, \mathrm{C}: 14 \mathrm{~s}^{\prime}=17594.94 \mathrm{~V} 114.64^{\circ}$ & $57:$ I, B: $14 s^{\prime}=6.87$ A -83.82 \\
\hline 28: V, A: I5e ' = $17553.03 \mathrm{~V}-5.85^{\circ}$ & 58: I, C: $14 s^{\prime}=10.15$ A $118.60^{\circ}$ \\
\hline 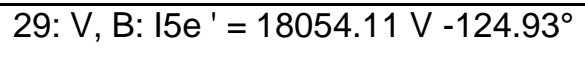 & $59:$ I, B: I5e ' = 1.93 A - $151.88^{\circ}$ \\
\hline $30: \mathrm{V}, \mathrm{C}: \mathrm{I5e} \mathrm{e}^{\prime}=17589.60 \mathrm{~V} 114.63^{\circ}$ & $60:$ I, C: I5e ' = 0.31 A $79.46^{\circ}$ \\
\hline
\end{tabular}


Table 10: Voltage and Current for PDS with 75\% DG and no faults

\begin{tabular}{|c|c|}
\hline \multicolumn{2}{|c|}{ No DG, No Fault } \\
\hline Voltage & Current \\
\hline 1: V, A: G2 ' = $19197.74 \mathrm{~V}-3.23^{\circ}$ & $31: \mathrm{I}, \mathrm{A}: \mathrm{G} 2{ }^{\prime}=7.83 \mathrm{~A}-40.91^{\circ}$ \\
\hline $2: \mathrm{V}, \mathrm{B}: \mathrm{G} 2 \mathrm{I}^{\prime}=19391.28 \mathrm{~V}-122.81^{\circ}$ & 32: I, A: G3 ' = 10.69 A $-39.28^{\circ}$ \\
\hline 3: V, C: G2 ' = 19235.57 V 116.90 & 33: I, A: G4 ' = 35.36 A $-37.27^{\circ}$ \\
\hline $4: \mathrm{V}, \mathrm{A}: \mathrm{G} 3 \mathrm{I}^{\prime}=19867.06 \mathrm{~V}-1.46^{\circ}$ & $34: \mathrm{I}, \mathrm{A}: 11 \mathrm{e}^{\prime}=17.82 \mathrm{~A}-0.90^{\circ}$ \\
\hline 5: V, B: G3 ' = 19982.40 V -121.29० & $35: I, A: I 1 s^{\prime}=17.85$ A $1.32^{\circ}$ \\
\hline 6: V, C: G3 ' = 19939.27 V 118.67º & $36: \mathrm{I}, \mathrm{A}: \mathrm{I} 2 \mathrm{e}^{\prime}=12.44 \mathrm{~A} 2.11^{\circ}$ \\
\hline $7: \mathrm{V}, \mathrm{A}: \mathrm{G} 4^{\prime}=19381.00 \mathrm{~V}-3.09^{\circ}$ & $37: \mathrm{I}, \mathrm{A}: \mathrm{I} \mathrm{Ie} \mathrm{e}^{\prime}=12.08 \mathrm{~A} 1.07^{\circ}$ \\
\hline $8: \mathrm{V}, \mathrm{B}: \mathrm{G} 4{ }^{\prime}=19563.12 \mathrm{~V}-122.69^{\circ}$ & $38: \mathrm{I}, \mathrm{A}: 14 \mathrm{e}^{\prime}=4.22 \mathrm{~A} 78.26^{\circ}$ \\
\hline 9: V, C: G4 ' = $19418.39 \mathrm{~V} 117.00^{\circ}$ & 39: I, A: I4s ' = $25.45 \mathrm{~A} 128.90^{\circ}$ \\
\hline $10: V, A: I 1 e^{\prime}=20264.72 \mathrm{~V}-0.32^{\circ}$ & $40: \mathrm{I}, \mathrm{A}: \mathrm{I5e} \mathrm{e}^{\prime}=34.39 \mathrm{~A} 142.61^{\circ}$ \\
\hline $11: \mathrm{V}, \mathrm{B}: \mathrm{I1 \textrm {e } ^ { \prime }}=20317.39 \mathrm{~V}-120.28^{\circ}$ & $41:$ I, B: G2 ' = $6.71 \mathrm{~A}-159.54^{\circ}$ \\
\hline $12: \mathrm{V}, \mathrm{C}: 11 \mathrm{e}^{\prime}=20308.29 \mathrm{~V} 119.76^{\circ}$ & 42: I, C: G2 ' = 7.57 A 78.95 \\
\hline $13: \mathrm{V}, \mathrm{A}: \mathrm{I} / \mathrm{s}^{\prime}=20412.12 \mathrm{~V}-0.01^{\circ}$ & 43: I, B: G3 ' = 8.93 A -155.87 \\
\hline $14: \mathrm{V}, \mathrm{B}: \mathrm{I1 \textrm {s } ^ { \prime }}=20412.23 \mathrm{~V}-120.01^{\circ}$ & $44:$ I, C: G3 ' = 9.50 A $82.24^{\circ}$ \\
\hline $15: \mathrm{V}, \mathrm{C}: 11 \mathrm{~s}^{\prime}=20412.33 \mathrm{~V} 119.99^{\circ}$ & 45: I, B: G4 ' = 30.09 A - $155.32^{\circ}$ \\
\hline $16: \mathrm{V}, \mathrm{A}: \mathrm{I2e} \mathrm{e}^{\prime}=19945.35 \mathrm{~V}-1.07^{\circ}$ & 46: I, C: G4 ' = 34.21 A $82.99^{\circ}$ \\
\hline $17: \mathrm{V}, \mathrm{B}: \mathrm{I} \mathrm{e}^{\prime}{ }^{\prime}=20087.11 \mathrm{~V}-120.93^{\circ}$ & $47: I, B: I 1 e^{\prime}=14.03 \mathrm{~A}-116.33^{\circ}$ \\
\hline $18: \mathrm{V}, \mathrm{C}: \mathrm{I2e} \mathrm{e}^{\prime}=20054.23 \mathrm{~V} 119.14^{\circ}$ & $48:$ I, C: $I 1 e^{\prime}=14.28$ A $125.24^{\circ}$ \\
\hline 19: V, A: I3e ' = 19867.06 V -1.46º & $49:$ I, B: I1s ' = $15.56 \mathrm{~A}-116.70^{\circ}$ \\
\hline $20: \mathrm{V}, \mathrm{B}: \mathrm{I3e} \mathrm{e}^{\prime}=19982.40 \mathrm{~V}-121.29^{\circ}$ & $50:$ I, C: I1s ' $=15.15$ A $125.82^{\circ}$ \\
\hline $21: \vee, C: \mid 3 e^{\prime}=19939.27$ V $118.67^{\circ}$ & $51: \mathrm{I}, \mathrm{B}: \mathrm{I} 2 \mathrm{e}^{\prime}=12.52 \mathrm{~A}-119.35^{\circ}$ \\
\hline $22: \mathrm{V}, \mathrm{A}: 14 \mathrm{e}^{\prime}=19290.33 \mathrm{~V}-3.26^{\circ}$ & $52: \mathrm{I}, \mathrm{C}: \mathrm{I} 2 \mathrm{e}^{\prime}=14.19 \mathrm{~A} 119.38^{\circ}$ \\
\hline $23: \mathrm{V}, \mathrm{B}: 14 \mathrm{e}^{\prime}=19509.20 \mathrm{~V}-122.81^{\circ}$ & $53:$ I, B: $\mid 3 e^{\prime}=11.95 \mathrm{~A}-119.95^{\circ}$ \\
\hline $24: \mathrm{V}, \mathrm{C}: 14 \mathrm{e}^{\prime}=19328.70 \mathrm{~V} 116.89^{\circ}$ & $54:$ I, C: I3e ' = 13.24 A $119.35^{\circ}$ \\
\hline $25: \mathrm{V}, \mathrm{A}: 14 \mathrm{~s}^{\prime}=19289.93 \mathrm{~V}-3.21^{\circ}$ & $55: \mathrm{I}, \mathrm{B}: 14 \mathrm{e}^{\prime}=4.11 \mathrm{~A}-52.03^{\circ}$ \\
\hline 26: V, B: I4s ' = 19497.06 V -122.76 & $56:$ I, C: $14 e^{\prime}=4.23 \mathrm{~A}-161.58^{\circ}$ \\
\hline $27: V, C: 14 s^{\prime}=19324.57$ V $116.92^{\circ}$ & $57:$ I, B: $14 s^{\prime}=28.88$ A $10.40^{\circ}$ \\
\hline $28: V, A: I 5 e^{\prime}=19381.00 \mathrm{~V}-3.09^{\circ}$ & $58:$ I, C: $14 s^{\prime}=26.31 \mathrm{~A}-112.10^{\circ}$ \\
\hline 29: V, B: I5e ' = 19563.12 V -122.69 & 59: I, B: I5e ' = 28.01 A $24.26^{\circ}$ \\
\hline $30: \mathrm{V}, \mathrm{C}: 15 \mathrm{e}^{\prime}=19418.39 \mathrm{~V} 117.00^{\circ}$ & $60:$ I, C: I5e ' = 33.86 A $-97.00^{\circ}$ \\
\hline
\end{tabular}

Where $\mathrm{V}, \mathrm{A}$ : $\mathrm{Gn}$ is the voltage of phase $\mathrm{A}$ of generator $\mathrm{n}$ $\mathrm{I}, \mathrm{A}: \mathrm{Gn}$ is the current of phase $\mathrm{A}$ of generator $\mathrm{n}$ 


\subsection{Results using Change of Current}

\section{Method}

After introducing faults in zone 2 and zone 5 the current data was measured to find the percentage change in each zone for each different type of fault. The following tables were obtained. 
Table 11: Change of Current Method with 3-phase Fault in Zone 2

\begin{tabular}{|c|c|c|c|c|c|c|c|c|c|c|c|c|c|}
\hline & \multirow{2}{*}{$\frac{\text { Data }}{\text { Phase }}$} & \multicolumn{3}{|c|}{ No DG } & \multicolumn{3}{|c|}{$25 \%$ DG } & \multicolumn{3}{|c|}{$50 \%$ DG } & \multicolumn{3}{|c|}{$75 \%$ DG } \\
\hline & & $A$ & B & $\mathrm{C}$ & $A$ & B & $\mathrm{C}$ & $A$ & B & $\mathrm{C}$ & $A$ & B & $\mathrm{C}$ \\
\hline \multirow[t]{3}{*}{ Zone 2} & Old Current & 4.65 & 0.84 & 0.69 & 5.05 & 1.07 & 0.47 & 5.33 & 1.33 & 0.18 & 5.39 & 1.51 & 0.1 \\
\hline & $\begin{array}{c}\text { New } \\
\text { Current }\end{array}$ & 739.6 & 739.6 & 739.2 & 675.6 & 674.8 & 677 & 474 & 473 & 474 & 399 & 398 & 399 \\
\hline & $\%$ Change & 15805.3 & 87947.6 & 107030.4 & 13278 & 62965 & 143942.5 & 8793 & 35463 & 263233.3 & 7302.5 & 26257.6 & 39890 \\
\hline \multirow[t]{3}{*}{ Zone 5} & Old Current & 9.13 & 4.52 & 8.81 & 9.94 & 4.83 & 6.11 & 10.27 & 4.96 & 9.84 & -8.95 & 0.86 & -7.57 \\
\hline & $\begin{array}{c}\text { New } \\
\text { Current }\end{array}$ & 0 & 0 & 0 & 2.5 & 1.2 & 2.42 & 4.43 & 2.29 & 4.17 & -6.5 & 0.9 & -5.8 \\
\hline & $\%$ Change & -100 & -100 & -100 & -74.8 & -75.1 & -60.3 & -56.8 & -53.8 & -57.6 & -27.3 & 4.6 & -23.3 \\
\hline
\end{tabular}

Table 12: Change of Current Method with 3-phase Fault in Zone 5

\begin{tabular}{|c|c|c|c|c|c|c|c|c|c|c|c|c|c|}
\hline & \multirow{2}{*}{$\begin{array}{l}\text { Data } \\
\text { Phase }\end{array}$} & \multicolumn{3}{|c|}{ No DG } & \multicolumn{3}{|c|}{$25 \%$ DG } & \multicolumn{3}{|c|}{$50 \%$ DG } & \multicolumn{3}{|c|}{$75 \%$ DG } \\
\hline & & A & B & C & A & B & $\mathrm{C}$ & $A$ & B & $\mathrm{C}$ & $A$ & B & $\mathrm{C}$ \\
\hline \multirow[t]{3}{*}{ Zone 2} & Old Current & 4.65 & 0.84 & 0.69 & 5.05 & 1.07 & 0.47 & 5.33 & 1.33 & 0.18 & 5.39 & 1.51 & 0.1 \\
\hline & New Current & 2.6 & 0.1 & 0.8 & 2.3 & 0.1 & 0.8 & 3.4 & 0.3 & -0.8 & 3.7 & 1 & 0.8 \\
\hline & \% Change & 44.0 & 88.0 & 15.9 & 54.4 & 90.6 & 70.2 & 36.2 & 77.4 & 544.4 & 31.3 & 33.7 & 700 \\
\hline \multirow[t]{3}{*}{ Zone 5} & Old Current & 9.13 & 4.52 & 8.81 & 9.94 & 4.83 & 6.11 & 10.27 & 4.96 & 9.84 & -8.95 & 0.86 & -7.57 \\
\hline & New Current & 199.8 & 200.3 & 200.7 & 275.9 & 275 & 276 & 318 & 317.8 & 319 & -150.6 & -150.4 & -149.6 \\
\hline & \% Change & 2088.3 & 4331.4 & 2178.0 & 2675.6 & 5593.5 & 4417.1 & 2996 & 6307.2 & 3141.8 & 1582.6 & 17388.3 & 1876.2 \\
\hline
\end{tabular}


Table 13: Change of Current Method with Line-Line (A, B) Fault in Zone 2

\begin{tabular}{|c|c|c|c|c|c|c|c|c|c|c|c|c|c|}
\hline & \multirow{2}{*}{$\begin{array}{l}\text { Data } \\
\text { Phase }\end{array}$} & \multicolumn{3}{|c|}{ No DG } & \multicolumn{3}{|c|}{$25 \%$ DG } & \multicolumn{3}{|c|}{$50 \%$ DG } & \multicolumn{3}{|c|}{$75 \%$ DG } \\
\hline & & $A$ & $B$ & $\mathrm{C}$ & $A$ & $B$ & $C$ & $A$ & B & $\mathrm{C}$ & $A$ & $B$ & $C$ \\
\hline \multirow[t]{3}{*}{ Zone 2} & Old Current & 4.65 & 0.84 & 0.69 & 5.05 & 1.07 & 0.47 & 5.33 & 1.33 & 0.18 & 5.39 & 1.51 & 0.1 \\
\hline & New Current & 619.2 & 615.28 & 0.74 & 607.3 & 562.2 & -0.4 & 431 & 392.2 & -0.2 & 357 & 333.9 & -0.1 \\
\hline & \% Change & 13216.1 & 73147.6 & 7.2 & 11925 & 52442 & -14.8 & 7986 & 29388 & 11.11 & 6523.3 & 22012.5 & 0 \\
\hline \multirow[t]{3}{*}{ Zone 5} & Old Current & 9.13 & 4.52 & 8.81 & 9.94 & 4.83 & 6.11 & 10.27 & 4.96 & 9.84 & -8.95 & 0.86 & -7.57 \\
\hline & New Current & 4.604 & 2.233 & 8.82 & 6.17 & 2.32 & 9.4 & 7.24 & 2.79 & 9.887 & -9.6 & 3.8 & -7.6 \\
\hline & \% Change & -49.5 & -50.5 & 0.11 & -37.92 & -51.96 & 53.84 & -29.5 & -43.75 & 0.47 & 7.26 & 341.86 & 0.396 \\
\hline
\end{tabular}

Table 14: Change of Current Method with Line-Line (A, B) Fault in Zone 5

\begin{tabular}{|c|c|c|c|c|c|c|c|c|c|c|c|c|c|}
\hline & \multirow{2}{*}{$\begin{array}{l}\text { Data } \\
\text { Phase }\end{array}$} & \multicolumn{3}{|c|}{ No DG } & \multicolumn{3}{|c|}{$25 \%$ DG } & \multicolumn{3}{|c|}{$50 \%$ DG } & \multicolumn{3}{|c|}{$75 \%$ DG } \\
\hline & & $A$ & B & $C$ & $A$ & $B$ & $C$ & $A$ & $B$ & $C$ & $A$ & $B$ & $C$ \\
\hline \multirow[t]{3}{*}{ Zone 2} & Old Current & 4.65 & 0.84 & 0.69 & 5.05 & 1.07 & 0.47 & 5.33 & 1.33 & 0.18 & 5.39 & 1.51 & 0.1 \\
\hline & New Current & 3.96 & 0.5 & 0.7 & 4 & 0.86 & 0.5 & 4.5 & 0.3 & 0.14 & 4.6 & -0.4 & -0.1 \\
\hline & \% Change & -14.83 & -40.4 & 1.44 & -20.79 & -19.62 & 6.38 & -15.57 & -77.44 & -22.2 & -14.6 & -73.5 & 0 \\
\hline \multirow[t]{3}{*}{ Zone 5} & Old Current & 9.13 & 4.52 & 8.81 & 9.94 & 4.83 & 6.11 & 10.27 & 4.96 & 9.84 & -8.95 & 0.86 & -7.57 \\
\hline & New Current & 176.5 & 170 & 9.1 & 242.5 & 234.6 & 9.5 & 280.1 & 272.1 & 9.89 & $\begin{array}{r}- \\
143.1 \\
\end{array}$ & -115.4 & -7.7 \\
\hline & $\%$ Change & 1833.18 & 3661.0 & 3.29 & 2339.63 & 4757.14 & 55.48 & 2627.36 & 5385.88 & 0.508 & 1498 & -13518 & 1.717 \\
\hline
\end{tabular}


Table 15: Change of Current Method with 3-phase Fault in Zone 2 through 10-ohm resistance

\begin{tabular}{|c|c|c|c|c|c|c|c|c|c|c|c|c|c|}
\hline & Data & \multicolumn{3}{|c|}{ No DG } & \multicolumn{3}{|c|}{$25 \%$ DG } & \multicolumn{3}{|c|}{$50 \%$ DG } & \multicolumn{3}{|c|}{$75 \%$ DG } \\
\hline & Phase & A & B & C & A & $B$ & C & A & $B$ & C & A & $B$ & C \\
\hline \multirow[t]{3}{*}{ Zone 2} & Old Current & 4.64 & 0.84 & 0.69 & 5.04 & 1.08 & 0.47 & 5.33 & 1.33 & 0.17 & 5.33 & 1.33 & 0.17 \\
\hline & New Current & 553.32 & 554.5 & $\begin{array}{r}553.3 \\
5\end{array}$ & 526.95 & 524.3 & 526.53 & 361.7 & 359.1 & 361.3 & 293.1 & 291.3 & 292.6 \\
\hline & $\%$ Change & 11825 & 65911 & $\begin{array}{r}8009 \\
5\end{array}$ & 10355.3 & 48446 & $\begin{array}{r}11192 \\
7\end{array}$ & 6686.1 & 26900 & $\begin{array}{r}2124 \\
29\end{array}$ & 5399 & 21802 & $\begin{array}{r}1720 \\
17\end{array}$ \\
\hline \multirow[t]{3}{*}{ Zone 5} & Old Current & 9.11 & 4.51 & 8.79 & 9.94 & 4.82 & 9.537 & 10.27 & 4.94 & 9.84 & 10.27 & 4.94 & 9.84 \\
\hline & New Current & 2.67 & 1.29 & 2.57 & 4.929 & 2.372 & 4.707 & 6.562 & 3.156 & 6.267 & -8.3 & 0 & -7.3 \\
\hline & $\%$ Change & -70.69 & -71.3 & -70.7 & -50.4 & -50.7 & -50.6 & -36.1 & -36.1 & -36.3 & -180 & -100 & -174 \\
\hline
\end{tabular}

Table 16: Change of Current Method with 3-phase Fault in Zone 5 through 10-ohm resistance

\begin{tabular}{|c|c|c|c|c|c|c|c|c|c|c|c|c|c|}
\hline & \multirow{2}{*}{$\begin{array}{l}\text { Data } \\
\text { Phase }\end{array}$} & \multicolumn{3}{|c|}{ No DG } & \multicolumn{3}{|c|}{$25 \%$ DG } & \multicolumn{3}{|c|}{$50 \%$ DG } & \multicolumn{3}{|c|}{$75 \%$ DG } \\
\hline & & A & B & C & $A$ & $B$ & C & A & $B$ & C & A & $B$ & C \\
\hline \multirow[t]{3}{*}{ Zone 2} & Old Current & 4.64 & 0.84 & 0.69 & 5.04 & 1.08 & 0.47 & 5.33 & 1.33 & 0.17 & 5.33 & 1.33 & 0.17 \\
\hline & New Current & 3.1 & 0.2 & 0.8 & 3.2 & 0.2 & 0.9 & 4 & 0.6 & 0.6 & 4.4 & 0.9 & 0.4 \\
\hline & $\%$ Change & 49.67 & 320 & -13 & 57.5 & 440 & -47.7 & 33.25 & 121.6 & -71.6 & 21.1 & 47.77 & -57.5 \\
\hline \multirow[t]{3}{*}{ Zone 5} & Old Current & 9.11 & 4.51 & 8.79 & 9.94 & 4.82 & 9.537 & 10.27 & 4.94 & 9.84 & 10.27 & 4.94 & 9.84 \\
\hline & New Current & 183.609 & 184.104 & 184 & 251.37 & 251.73 & 252.2 & 289.456 & 289.49 & 290. & -139 & -138.7 & -138 \\
\hline & \% Change & -1915.4 & -3982.1 & 1999 & -2428.8 & -5122.6 & -2545. & -2718.4 & -5760.1 & -2847 & 1458 & 2907 & 1502 \\
\hline
\end{tabular}


Table 17: Change of Current Method with single phase Fault in Zone 2

\begin{tabular}{|c|c|c|c|c|c|c|c|c|c|c|c|c|c|}
\hline & \multirow{2}{*}{$\begin{array}{l}\text { Data } \\
\text { Phase }\end{array}$} & \multicolumn{3}{|c|}{ No DG } & \multicolumn{3}{|c|}{$25 \% \mathrm{DG}$} & \multicolumn{3}{|c|}{$50 \%$ DG } & \multicolumn{3}{|c|}{$75 \%$ DG } \\
\hline & & $A$ & B & $C$ & $A$ & $B$ & $\mathrm{C}$ & $A$ & $B$ & $C$ & $A$ & $B$ & $\mathrm{C}$ \\
\hline \multirow[t]{3}{*}{ Zone 2} & Old Current & 4.65 & 0.84 & 0.69 & 5.05 & 1.07 & 0.47 & 5.33 & 1.33 & 0.18 & 5.39 & 1.51 & 0.1 \\
\hline & New Current & 543.6 & 1.017 & 0.504 & 496.8 & 1.075 & 0.2669 & 331.4 & 0.5915 & 0.234 & 275.5 & 0.5779 & 0.470 \\
\hline & \% Change & 11590.32258 & 21.071 & -26.8 & 9737.6 & 0.4672 & -43.2 & 6117.63 & -55.52 & 30.27 & 5011 & -61.72 & 370.7 \\
\hline \multirow[t]{3}{*}{ Zone 5} & Old Current & 9.13 & 4.52 & 8.81 & 9.94 & 4.83 & 6.11 & 10.27 & 4.96 & 9.84 & -8.95 & 0.86 & -7.57 \\
\hline & New Current & 0.778 & 5.156 & 9.579 & 3.605 & 5.168 & 9.555 & 5.496 & 5.011 & 9.643 & -5.58 & 3.004 & -8.47 \\
\hline & \% Change & -91.478 & 14.07 & 8.728 & -63.73 & 6.997 & 56.38 & -46.48 & 1.028 & -2.00 & -37.5 & 249.302 & 11.92 \\
\hline
\end{tabular}

Table 18: Change of Current Method with single phase Fault in Zone 5

\begin{tabular}{|c|c|c|c|c|c|c|c|c|c|c|c|c|c|}
\hline & \multirow{2}{*}{$\begin{array}{l}\text { Data } \\
\text { Phase }\end{array}$} & \multicolumn{3}{|c|}{ No DG } & \multicolumn{3}{|c|}{$25 \% \mathrm{DG}$} & \multicolumn{3}{|c|}{$50 \%$ DG } & \multicolumn{3}{|c|}{$75 \%$ DG } \\
\hline & & $A$ & B & $C$ & $A$ & $B$ & $\mathrm{C}$ & $A$ & $B$ & $C$ & $A$ & $B$ & $C$ \\
\hline \multirow[t]{3}{*}{ Zone 2} & Old Current & 4.65 & 0.84 & 0.69 & 5.05 & 1.07 & 0.47 & 5.33 & 1.33 & 0.18 & 5.39 & 1.51 & 0.1 \\
\hline & New Current & 2.471 & 0.75 & 0.519 & 2.558 & 0.56 & -0.234 & 3.555 & 0.427 & 0.109 & 3.583 & -0.3164 & 0.442 \\
\hline & \% Change & -46.860 & -10.71 & -24.7 & -49.3 & -47.66 & -50.21 & -33.30 & -67.89 & -39.4 & -33.5 & -79.04 & 342.7 \\
\hline \multirow[t]{3}{*}{ Zone 5} & Old Current & 9.13 & 4.52 & 8.81 & 9.94 & 4.83 & 6.11 & 10.27 & 4.96 & 9.84 & -8.95 & 0.86 & -7.57 \\
\hline & New Current & 146.3 & 5.381 & 9.749 & 227.4 & 5.527 & 9.917 & 263.4 & 5.635 & 10.26 & -191 & -5.945 & 3.613 \\
\hline & \% Change & 1502.40 & 19.048 & 10.65 & 2187.72 & 14.430 & 62.30 & 2464.75 & 13.608 & 4.268 & 2036 & -791.27 & -147 \\
\hline
\end{tabular}


Setting the threshold at $70 \%$, this method can be reliable if the load power supplied by the DG is $50 \%$ or below. Also, the location of the fault affects the method. If the fault is far from the main source (main power generator), the method tends to fail. When the fault was introduced in Zone 5 with $50 \%$ of power load supplied by the DGs, the method failed as it identified the location of a fault in zone 2 and zone 5. This happened for both types of faults tested (three-phase fault and Line-Line fault between phase A and B). When this method was tested for three-phase fault through 10-ohm resistance, it worked only when the fault was in zone 2 and was not able to work right when the fault was in zone 5 . If the fault is single phase to ground, the method will be able to detect it until we have the power injected by the DGs about $75 \%$.

According to the results, change of current method, can be used for PS to identify faults location with a limited amount of power injected (DGs). As the fault occurs far away from the main power source, it will be harder to identify the fault location or even the method may identify the wrong location for the faults.

\subsection{Results using Symmetrical}

\section{Components Method}

The following table was obtained from performing this method. 
Table 19: Symmetrical Components Method with 3-phase Fault in Zone 2

\begin{tabular}{|c|c|c|c|c|c|c|c|c|c|c|c|c|c|}
\hline & & \multicolumn{3}{|c|}{ No DG } & \multicolumn{3}{|c|}{$25 \%$ DG } & \multicolumn{3}{|c|}{$50 \%$ DG } & \multicolumn{3}{|c|}{$75 \%$ DG } \\
\hline & & $\begin{array}{l}\text { Positive } \\
\text { Seq }\end{array}$ & $\begin{array}{c}\text { Negative } \\
\text { Seq }\end{array}$ & $\begin{array}{l}\text { Zero } \\
\text { Seq }\end{array}$ & $\begin{array}{l}\text { Positive } \\
\text { Seq }\end{array}$ & $\begin{array}{c}\text { Negative } \\
\text { Seq }\end{array}$ & $\begin{array}{l}\text { Zero } \\
\text { Seq }\end{array}$ & $\begin{array}{l}\text { Positive } \\
\text { Seq }\end{array}$ & $\begin{array}{c}\text { Negative } \\
\text { Seq }\end{array}$ & $\begin{array}{l}\text { Zero } \\
\text { Seq }\end{array}$ & $\begin{array}{c}\text { Positive } \\
\text { Seq }\end{array}$ & $\begin{array}{c}\text { Negative } \\
\text { Seq }\end{array}$ & $\begin{array}{l}\text { Zero } \\
\text { Seq }\end{array}$ \\
\hline \multirow[t]{3}{*}{ Zone 2} & Old Diff & 1.595 & 0.3401 & 1.448 & 1.872 & 0.6019 & 1.317 & 2.148 & 0.8067 & $\begin{array}{c}0.783 \\
7\end{array}$ & 2.308 & 0.9365 & 0.512 \\
\hline & New Diff & 739.2 & 0.4652 & 0.0490 & 673.8 & 0.005094 & -0.216 & 473.9 & -0.2126 & 0.022 & 398 & -0.1021 & -0.0152 \\
\hline & \% change & 46244.8 & 36.7 & -96.6 & 35893.5 & -99.1 & -83.5 & 21962.3 & -73.6 & -97.1 & 17144.3 & -89.0 & -97.0 \\
\hline \multirow[t]{3}{*}{ Zone 5} & Old Diff & 7.021 & 1.921 & 1.548 & 7.612 & 2.089 & 1.731 & 7.847 & 2.156 & 1.799 & -5.169 & -0.8572 & -1.14 \\
\hline & New Diff & 0 & 0 & 0 & 1.998 & 0.5467 & 0.4603 & 3.319 & 0.9083 & 0.765 & -3.336 & -0.5432 & -0.7482 \\
\hline & $\%$ change & -100 & -100 & -100 & -73.7 & $\begin{array}{l}-73.8 \\
\end{array}$ & $\begin{array}{l}-73.4 \\
\end{array}$ & -57.7 & $\begin{array}{l}-57.8 \\
\end{array}$ & -57.4 & -35.4 & -36.6 & -34.3 \\
\hline
\end{tabular}

Table 20: Symmetrical Components Method with 3-phase Fault in Zone 5

\begin{tabular}{|c|c|c|c|c|c|c|c|c|c|c|c|c|c|}
\hline & & \multicolumn{3}{|c|}{ No DG } & \multicolumn{3}{|c|}{$25 \%$ DG } & \multicolumn{3}{|c|}{$50 \%$ DG } & \multicolumn{3}{|c|}{$75 \%$ DG } \\
\hline & & $\begin{array}{c}\text { Positive } \\
\text { Seq }\end{array}$ & $\begin{array}{l}\text { Negative } \\
\text { Seq }\end{array}$ & $\begin{array}{l}\text { Zero } \\
\text { Seq }\end{array}$ & $\begin{array}{c}\text { Positive } \\
\text { Seq }\end{array}$ & $\begin{array}{l}\text { Negative } \\
\text { Seq }\end{array}$ & $\begin{array}{l}\text { Zero } \\
\text { Seq }\end{array}$ & $\begin{array}{c}\text { Positive } \\
\text { Seq }\end{array}$ & $\begin{array}{l}\text { Negative } \\
\text { Seq }\end{array}$ & $\begin{array}{l}\text { Zero } \\
\text { Seq }\end{array}$ & $\begin{array}{c}\text { Positive } \\
\text { Seq }\end{array}$ & $\begin{array}{l}\text { Negative } \\
\text { Seq }\end{array}$ & $\begin{array}{l}\text { Zero } \\
\text { Seq }\end{array}$ \\
\hline \multirow[t]{3}{*}{ Zone 2} & Old Diff & 1.595 & 0.3401 & 1.448 & 1.872 & 0.6019 & 1.317 & 2.148 & 0.8067 & $\begin{array}{c}0.783 \\
7\end{array}$ & 2.308 & 0.9365 & 0.512 \\
\hline & New Diff & 0.6038 & 0.67 & 0.5904 & 0.6347 & 0.6684 & 0.5918 & 1.057 & 0.4647 & 0.299 & 1.057 & 0.4647 & 0.3 \\
\hline & $\%$ change & -62.1 & 97.0 & -59.2 & -66.1 & 11.0 & -55.1 & -50.8 & -42.4 & -61.7 & -54.2 & -50.3 & -41.4 \\
\hline \multirow[t]{3}{*}{ Zone 5} & Old Diff & 7.021 & 1.921 & 1.548 & 7.612 & 2.089 & 1.731 & 7.847 & 2.156 & 1.799 & -5.169 & -0.8572 & -1.14 \\
\hline & New Diff & 199.7 & 0.1712 & 0.2657 & 275.4 & 0.1194 & 0.2519 & 318.3 & 0.04538 & 0.142 & -148.3 & -0.2075 & 0.1264 \\
\hline & \% change & 2744.3 & -91.1 & -82.8 & 3517.9 & -94.2 & -85.4 & 3956.3 & -97.8 & -92.0 & 2769.0 & -75.7 & -88.9 \\
\hline
\end{tabular}


Table 21: Symmetrical Components Method with Line-Line (A, B) Fault in Zone 2

\begin{tabular}{|c|c|c|c|c|c|c|c|c|c|c|c|c|c|}
\hline & & \multicolumn{3}{|c|}{ No DG } & \multicolumn{3}{|c|}{$25 \%$ DG } & \multicolumn{3}{|c|}{$50 \%$ DG } & \multicolumn{3}{|c|}{$75 \%$ DG } \\
\hline & & $\begin{array}{c}\text { Positive } \\
\text { Seq }\end{array}$ & $\begin{array}{l}\text { Negative } \\
\text { Seq }\end{array}$ & $\begin{array}{c}\text { Zero } \\
\text { Seq }\end{array}$ & $\begin{array}{c}\text { Positive } \\
\text { Seq }\end{array}$ & $\begin{array}{c}\text { Negative } \\
\text { Seq }\end{array}$ & $\begin{array}{c}\text { Zero } \\
\text { Seq }\end{array}$ & $\begin{array}{c}\text { Positive } \\
\text { Seq }\end{array}$ & $\begin{array}{l}\text { Negative } \\
\text { Seq }\end{array}$ & $\begin{array}{c}\text { Zero } \\
\text { Seq }\end{array}$ & $\begin{array}{c}\text { Positive } \\
\text { Seq }\end{array}$ & $\begin{array}{c}\text { Negative } \\
\text { Seq }\end{array}$ & $\begin{array}{c}\text { Zero } \\
\text { Seq }\end{array}$ \\
\hline \multirow[t]{3}{*}{ Zone 2} & Old Diff & 1.595 & 0.3401 & 1.448 & 1.872 & 0.6019 & 1.317 & 2.148 & 0.8067 & 0.78 & 2.308 & 0.9365 & 0.512 \\
\hline & New Diff & 370 & 318 & -0.23 & 362.3 & 303.5 & 0.2331 & 254.5 & 218.9 & 0.03 & 207.1 & 191 & 0.06574 \\
\hline & \% change & 23097.5 & 93401.9 & -83.6 & 19253.6 & 50323.6 & -82.3 & 11748.2 & 27035.2 & -95.3 & 8873.1 & 20295.1 & -87.2 \\
\hline \multirow[t]{3}{*}{ Zone 5} & Old Diff & 7.021 & 1.921 & 1.548 & 7.612 & 2.089 & 1.731 & 7.847 & 2.156 & 1.799 & -5.169 & -0.8572 & -1.14 \\
\hline & New Diff & 3.241 & 4.753 & 0.3644 & 4.682 & 4.633 & 0.3225 & 5.534 & 4.403 & 0.547 & -3.949 & 0.2379 & -0.7158 \\
\hline & $\%$ change & -53.8 & 147.4 & -76.5 & -38.5 & 121.7 & -81.3 & -29.4 & 104.2 & -69.5 & -23.6 & -72.2 & -37.2 \\
\hline
\end{tabular}

Table 22: Symmetrical Components Method with Line-Line (A, B) Fault in Zone 5

\begin{tabular}{|c|c|c|c|c|c|c|c|c|c|c|c|c|c|}
\hline & & \multicolumn{3}{|c|}{ No DG } & \multicolumn{3}{|c|}{$25 \%$ DG } & \multicolumn{3}{|c|}{$50 \%$ DG } & \multicolumn{3}{|c|}{$75 \%$ DG } \\
\hline & & $\begin{array}{c}\text { Positive } \\
\text { Seq }\end{array}$ & $\begin{array}{c}\text { Negative } \\
\text { Seq }\end{array}$ & $\begin{array}{l}\text { Zero } \\
\text { Seq }\end{array}$ & $\begin{array}{c}\text { Positive } \\
\text { Seq }\end{array}$ & $\begin{array}{c}\text { Negative } \\
\text { Seq }\end{array}$ & $\begin{array}{l}\text { Zero } \\
\text { Seq }\end{array}$ & $\begin{array}{c}\text { Positive } \\
\text { Seq }\end{array}$ & $\begin{array}{c}\text { Negative } \\
\text { Seq }\end{array}$ & $\begin{array}{l}\text { Zero } \\
\text { Seq }\end{array}$ & $\begin{array}{c}\text { Positive } \\
\text { Seq }\end{array}$ & $\begin{array}{c}\text { Negative } \\
\text { Seq }\end{array}$ & $\begin{array}{r}\text { Zero } \\
\text { Seq } \\
\end{array}$ \\
\hline \multirow[t]{3}{*}{ Zone 2} & Old Diff & 1.595 & 0.3401 & 1.448 & 1.872 & 0.6019 & 1.317 & 2.148 & 0.8067 & $\begin{array}{c}0.783 \\
7\end{array}$ & 2.308 & 0.9365 & 0.512 \\
\hline & New Diff & 0.8099 & 1.263 & 0.4573 & 0.8685 & 1.268 & 0.4261 & 1.262 & 1.313 & 0.143 & 1.236 & 1.289 & 0.210 \\
\hline & \% change & -49.2 & 271.3 & -68.4 & -53.6 & 110.6 & -67.6 & -41.2 & 62.7 & -81.6 & -46.4 & 37.6 & -58.8 \\
\hline \multirow[t]{3}{*}{ Zone 5} & Old Diff & 7.021 & 1.921 & 1.548 & 7.612 & 2.089 & 1.731 & 7.847 & 2.156 & 1.799 & -5.169 & -0.8572 & -1.14 \\
\hline & New Diff & 102.2 & 96.8 & 0.3334 & 139.5 & 135.1 & 0.3721 & 160.9 & 156.7 & 0.384 & -99.26 & -50.02 & -0.50 \\
\hline & \% change & 1355.6 & 4939.0 & -78.4 & 1732.6 & 6367.2 & -78.5 & 1950.4 & 7168.1 & -78.6 & 1820.3 & 5735.3 & -55.4 \\
\hline
\end{tabular}


Table 23: Symmetrical Components Method with 3-phase Fault in Zone 2 through 10-ohm resistance

\begin{tabular}{|c|c|c|c|c|c|c|c|c|c|c|c|c|c|}
\hline & & \multicolumn{3}{|c|}{ No DG } & \multicolumn{3}{|c|}{$25 \%$ DG } & \multicolumn{3}{|c|}{$50 \%$ DG } & \multicolumn{3}{|c|}{$75 \%$ DG } \\
\hline & & $\begin{array}{c}\text { Positive } \\
\text { Seq }\end{array}$ & $\begin{array}{c}\text { Negative } \\
\text { Seq }\end{array}$ & $\begin{array}{c}\text { Zero } \\
\text { Seq }\end{array}$ & $\begin{array}{c}\text { Positive } \\
\text { Seq }\end{array}$ & $\begin{array}{c}\text { Negative } \\
\text { Seq }\end{array}$ & $\begin{array}{c}\text { Zero } \\
\text { Seq }\end{array}$ & $\begin{array}{c}\text { Positive } \\
\text { Seq }\end{array}$ & $\begin{array}{c}\text { Negative } \\
\text { Seq }\end{array}$ & $\begin{array}{c}\text { Zero } \\
\text { Seq }\end{array}$ & $\begin{array}{c}\text { Positive } \\
\text { Seq }\end{array}$ & $\begin{array}{c}\text { Negative } \\
\text { Seq }\end{array}$ & $\begin{array}{c}\text { Zero } \\
\text { Seq }\end{array}$ \\
\hline \multirow[t]{3}{*}{ Zone 2} & Old Diff & 1.595 & 0.3401 & 1.448 & 1.872 & 0.6019 & 1.317 & 2.148 & 0.8067 & $\begin{array}{c}0.783 \\
7\end{array}$ & 2.308 & 0.9365 & 0.512 \\
\hline & New Diff & 553.4 & -0.351 & -0.316 & 398.8 & -0.47 & -0.38 & 360.8 & -0.46 & -0.35 & 292.6 & -0.184 & -0.21 \\
\hline & \% change & 34595 & 3.20 & -78.17 & 21203.4 & -21.9 & -71.14 & 16697.0 & -42.97 & -55.3 & 12577. & -80.3 & -57.8 \\
\hline \multirow[t]{3}{*}{ Zone 5} & Old Diff & 7.021 & 1.921 & 1.548 & 7.612 & 2.089 & 1.731 & 7.847 & 2.156 & 1.799 & -5.169 & -0.8572 & -1.14 \\
\hline & New Diff & 2.06 & 0.56 & 0.466 & 3.73 & 1.02 & 0.85 & 5.01 & 1.368 & 1.154 & -5.138 & -0.57 & -0.83 \\
\hline & \% change & -70.65 & -70.84 & -69.89 & -50.99 & -51.17 & -50.89 & -36.15 & -36.54 & -35.8 & -0.59 & -33.50 & -27.1 \\
\hline
\end{tabular}

Table 24: Symmetrical Components Method with 3-phase Fault in Zone 5 through 10-ohm resistance

\begin{tabular}{|c|c|c|c|c|c|c|c|c|c|c|c|c|c|}
\hline & & \multicolumn{3}{|c|}{ No DG } & \multicolumn{3}{|c|}{$25 \%$ DG } & \multicolumn{3}{|c|}{$50 \%$ DG } & \multicolumn{3}{|c|}{$75 \%$ DG } \\
\hline & & $\begin{array}{c}\text { Positive } \\
\text { Seq }\end{array}$ & $\begin{array}{c}\text { Negative } \\
\text { Seq } \\
\end{array}$ & $\begin{array}{c}\text { Zero } \\
\text { Seq }\end{array}$ & $\begin{array}{c}\text { Positive } \\
\text { Seq }\end{array}$ & $\begin{array}{c}\text { Negative } \\
\text { Seq } \\
\end{array}$ & $\begin{array}{c}\text { Zero } \\
\text { Seq }\end{array}$ & $\begin{array}{c}\text { Positive } \\
\text { Seq }\end{array}$ & $\begin{array}{c}\text { Negative } \\
\text { Seq } \\
\end{array}$ & $\begin{array}{c}\text { Zero } \\
\text { Seq }\end{array}$ & $\begin{array}{c}\text { Positive } \\
\text { Seq }\end{array}$ & $\begin{array}{c}\text { Negative } \\
\text { Seq } \\
\end{array}$ & $\begin{array}{c}\text { Zero } \\
\text { Seq }\end{array}$ \\
\hline \multirow[t]{3}{*}{ Zone 2} & Old Diff & 1.595 & 0.3401 & 1.448 & 1.872 & 0.6019 & 1.317 & 2.148 & 0.8067 & 0.783 & 2.308 & 0.9365 & 0.512 \\
\hline & New Diff & 0.95 & 1.27 & 0.71 & 1.38 & 1.28 & 0.27 & 1.47 & 1.25 & 0.27 & 1.73 & 1.05 & 0.34 \\
\hline & \% change & -40.43 & 273.41 & -50.9 & -26.2 & 112.6 & -79.4 & -31.5 & 54.9 & -65.5 & -25.0 & 12.11 & -33.5 \\
\hline \multirow[t]{3}{*}{ Zone 5} & Old Diff & 7.021 & 1.921 & 1.548 & 7.612 & 2.089 & 1.731 & 7.847 & 2.156 & 1.799 & -5.169 & -0.8572 & -1.14 \\
\hline & New Diff & 94.5 & 88.54 & 0.195 & 112.9 & 107.2 & 0.184 & 146.9 & 141.4 & 0.151 & -97.22 & -41.72 & -0.37 \\
\hline & $\%$ change & 1245.9 & 4509.0 & -87.4 & 1383.18 & 5031.6 & -89.3 & 1772.0 & 6458.4 & -91.6 & 1780.8 & 4767.0 & -67.5 \\
\hline
\end{tabular}


Table 25: Symmetrical Components Method with single phase to ground fault in zone 2

\begin{tabular}{|c|c|c|c|c|c|c|c|c|c|c|c|c|c|}
\hline & & \multicolumn{3}{|c|}{ No DG } & \multicolumn{3}{|c|}{$25 \%$ DG } & \multicolumn{3}{|c|}{$50 \%$ DG } & \multicolumn{3}{|c|}{$75 \%$ DG } \\
\hline & & $\begin{array}{c}\text { Positive } \\
\text { Seq }\end{array}$ & $\begin{array}{c}\text { Negative } \\
\text { Seq }\end{array}$ & $\begin{array}{c}\text { Zero } \\
\text { Seq }\end{array}$ & $\begin{array}{c}\text { Positive } \\
\text { Seq }\end{array}$ & $\begin{array}{c}\text { Negative } \\
\text { Seq }\end{array}$ & $\begin{array}{l}\text { Zero } \\
\text { Seq }\end{array}$ & $\begin{array}{c}\text { Positive } \\
\text { Seq }\end{array}$ & $\begin{array}{c}\text { Negative } \\
\text { Seq }\end{array}$ & $\begin{array}{c}\text { Zero } \\
\text { Seq }\end{array}$ & $\begin{array}{c}\text { Positive } \\
\text { Seq }\end{array}$ & $\begin{array}{c}\text { Negative } \\
\text { Seq }\end{array}$ & $\begin{array}{c}\text { Zero } \\
\text { Seq }\end{array}$ \\
\hline \multirow[t]{3}{*}{ Zone 2} & Old Diff & 1.595 & 0.3401 & 1.448 & 1.872 & 0.6019 & 1.317 & 2.148 & 0.8067 & 0.783 & 2.308 & 0.9365 & 0.512 \\
\hline & New Diff & 180.4 & 157.5 & 147 & 181.9 & 153 & 134.8 & 140.3 & 115.1 & 70.64 & 109.1 & 97.92 & 67.13 \\
\hline & \% change & 11210.3 & 46209.9 & 10051.9 & 9616.88 & 25319.5 & 10135 & 6431.6 & 14168.0 & 8913 & 4627.0 & 10355. & 1301 \\
\hline \multirow[t]{3}{*}{ Zone 5} & Old Diff & 7.021 & 1.921 & 1.548 & 7.612 & 2.089 & 1.731 & 7.847 & 2.156 & 1.799 & -5.169 & -0.8572 & -1.14 \\
\hline & New Diff & 5.09 & 2.76 & 1.35 & 5.76 & 2.65 & -0.191 & 6.213 & 2.624 & 0.05 & -3.14 & -2.89 & -0.42 \\
\hline & \% change & -27.50 & 43.675 & -12.79 & -24.33 & 26.85 & -88.9 & -20.82 & 21.70 & -97.2 & -39.2 & 237.1 & -63.1 \\
\hline
\end{tabular}

Table 26: Symmetrical Components Method with single phase to ground fault in zone 5

\begin{tabular}{|c|c|c|c|c|c|c|c|c|c|c|c|c|c|}
\hline & & \multicolumn{3}{|c|}{ No DG } & \multicolumn{3}{|c|}{$25 \%$ DG } & \multicolumn{3}{|c|}{$50 \%$ DG } & \multicolumn{3}{|c|}{$75 \%$ DG } \\
\hline & & $\begin{array}{c}\text { Positive } \\
\text { Seq }\end{array}$ & $\begin{array}{c}\text { Negative } \\
\text { Seq }\end{array}$ & $\begin{array}{l}\text { Zero } \\
\text { Seq }\end{array}$ & $\begin{array}{c}\text { Positive } \\
\text { Seq }\end{array}$ & $\begin{array}{c}\text { Negative } \\
\text { Seq }\end{array}$ & $\begin{array}{l}\text { Zero } \\
\text { Seq }\end{array}$ & $\begin{array}{c}\text { Positive } \\
\text { Seq }\end{array}$ & $\begin{array}{c}\text { Negative } \\
\text { Seq }\end{array}$ & $\begin{array}{l}\text { Zero } \\
\text { Seq }\end{array}$ & $\begin{array}{c}\text { Positive } \\
\text { Seq }\end{array}$ & $\begin{array}{c}\text { Negative } \\
\text { Seq }\end{array}$ & $\begin{array}{l}\text { Zero } \\
\text { Seq }\end{array}$ \\
\hline \multirow[t]{3}{*}{ Zone 2} & Old Diff & 1.595 & 0.3401 & 1.448 & 1.872 & 0.6019 & 1.317 & 2.148 & 0.8067 & 0.783 & 2.308 & 0.9365 & 0.512 \\
\hline & New Diff & 0.8715 & 0.5584 & 1.033 & 0.9245 & 0.6019 & 1.069 & 1.351 & 0.95 & 1.3 & 1.29 & 1.07 & 1.302 \\
\hline & $\%$ change & -45.36 & 64.18 & -28.66 & -50.61 & 0 & -18.83 & -37.10 & 17.763 & 65.87 & -44.10 & 14.25 & 154.2 \\
\hline \multirow[t]{3}{*}{ Zone 5} & Old Diff & 7.021 & 1.921 & 1.548 & 7.612 & 2.089 & 1.731 & 7.847 & 2.156 & 1.799 & -5.169 & -0.8572 & -1.14 \\
\hline & New Diff & 49.56 & 48.04 & 46.76 & 75.6 & 75.41 & 74.04 & 87.26 & 87.57 & 86 & -79.06 & -31.61 & -880 \\
\hline & $\%$ change & 605.8 & 2400.7 & 2920.67 & 893.16 & 3509.8 & 4177.2 & 1012.01 & 3961.6 & 4680 & 1429.5 & 3587.5 & 7714 \\
\hline
\end{tabular}


It is observed from the tables above that the type of the fault affects the symmetrical components. If a three-phase fault occurs, only the positive current will be affected by the fault. If a Line-Line fault occurs, both positive and negative sequence currents will be affected. By observing the change in the symmetrical component, the fault location and type will be detected. It is also observed that if a fault occurs in zone 2, the other zones will be affected by the same amount of change in all of the symmetrical components. The location of the fault can be detected by observing the change in the all of the current sequence currents.

For three-phase fault through a resistance of 10 -ohm this method was able to detect the fault when it was in zone 2 (near the main power source). When the fault occurred in zone 5 , the method could not identify the fault location exactly.

For single line to ground fault the method will be able to detect the fault if the power injected by the DGs is less than $75 \%$. When the power injected by the DG exceeds $75 \%$, the method tends to see the fault as if it occurs in both of the zones

The method is reliable if the fault is a three-phase fault. The method failed to detect the location of the fault while increasing the percentage of load power supplied by the DGs in the power system. 


\subsection{Results using ANN}

Testing the Artificial intelligence method required training the network before using it. For each case, a new network has been trained to obtain the best result. And for each of the cases the fault was introduced in one of the zones $(2,5)$ and these cases are:

- NO power is supplied by the DGs

- $25 \%$ of load power is supplied by the DGs

- $50 \%$ of load power is supplied by the DGs

- $75 \%$ of load power is supplied by the DGs 
Table 27: Training Data and Result with NO DG for 3-phase Fault and LL Fault

\begin{tabular}{|c|c|c|c|c|c|c|c|c|c|c|c|c|c|c|c|c|}
\hline & Data & \multicolumn{3}{|c|}{ No Fault } & \multicolumn{3}{|c|}{ 3-Ph Fault @ Z2 } & \multicolumn{3}{|c|}{ LL Fault @ Z2 } & \multicolumn{3}{|c|}{ 3-Ph Fault @Z5 } & \multicolumn{3}{|c|}{ LL Fault @Z5 } \\
\hline \multirow[t]{2}{*}{ Zone 2} & I1e & 56.82 & 48.61 & 52.14 & 741.1 & 740.9 & 741.1 & 645.6 & 639 & 52.25 & 206.3 & 204.3 & 204.8 & 189.6 & 170.1 & 52.25 \\
\hline & $12 \mathrm{e}$ & 52.18 & 47.77 & 51.45 & 0.002 & 0.0018 & 0.00203 & 26.41 & 23.65 & 51.56 & 203.6 & 204.3 & 203.9 & 185.6 & 170.6 & 51.55 \\
\hline \multirow[t]{2}{*}{ Zone 5} & $14 \mathrm{~s}$ & 9.89 & 6.27 & 9.07 & 0 & 0 & 0 & 5.02 & 3.09 & 9.12 & 199.8 & 200.4 & 200.7 & 176.5 & 170 & 9.13 \\
\hline & $15 e$ & 0.78 & 1.76 & 0.28 & 0 & 0 & 0 & 0.39 & 0.87 & 0.28 & 0.00001 & 0.000021 & 0.0000036 & 0.402 & 0.86 & 0.28 \\
\hline \multicolumn{2}{|c|}{ Target } & 0 & 0 & 0 & 10 & 10 & 10 & 20 & 20 & 0 & 30 & 30 & 30 & 40 & 40 & 0 \\
\hline
\end{tabular}

\begin{tabular}{|c|c|c|c|c|c|c|c|c|c|c|c|c|c|c|c|}
\hline Target & 0 & 0 & 0 & 10 & 10 & 10 & 20 & 20 & 0 & 30 & 30 & 30 & 40 & 40 & 0 \\
\hline Network Result & 0.00 & 0.00 & 0.00 & 10.00 & 10.00 & 10.00 & 20.00 & 20.00 & 0.00 & 30.00 & 30.00 & 30.14 & 39.90 & 40.00 & 0.00 \\
\hline Error \% & 0.00 & 0.00 & 0.00 & 0.00 & 0.00 & 0.00 & 0.00 & 0.00 & 0.00 & 0.00 & 0.00 & 14.30 & -10.00 & 0.00 & 0.00 \\
\hline
\end{tabular}

Table 28: Training Data and Result with 25\% DG for 3-phase Fault and LL Fault

\begin{tabular}{|c|c|c|c|c|c|c|c|c|c|c|c|c|c|c|c|c|}
\hline \multicolumn{2}{|r|}{ Data } & \multicolumn{3}{|c|}{ No Fault } & \multicolumn{3}{|c|}{ 3-Ph Fault @ Z2 } & \multicolumn{3}{|c|}{ LL Fault @ Z2 } & \multicolumn{3}{|c|}{ 3-Ph Fault @Z5 } & \multicolumn{3}{|c|}{ LL Fault @Z5 } \\
\hline \multirow[t]{2}{*}{ Zone 2} & I1e & 45.07 & 38.19 & 40.73 & 741.1 & 740.9 & 741.1 & 648.4 & 635.8 & 40.73 & 202.6 & 200.5 & 201 & 186.6 & 165 & 40.68 \\
\hline & $12 \mathrm{e}$ & 40.03 & 37.11 & 40.26 & 65.14 & 66.32 & 65.47 & 41.11 & 73.62 & 40.26 & 199.8 & 200.5 & 200.1 & 182.6 & 165 & 40.68 \\
\hline \multirow[t]{2}{*}{ Zone 5} & $14 \mathrm{~s}$ & 10.79 & 6.69 & 9.84 & 2.85 & 1.74 & 2.58 & 6.68 & 3.15 & 9.88 & 275.9 & 276.4 & 276.7 & 242.9 & 235.3 & 9.89 \\
\hline & $15 \mathrm{e}$ & 0.85 & 1.87 & 0.303 & 0.22 & 0.49 & 0.08 & 0.53 & 0.88 & 0.304 & 0.00001 & 0.000029 & 0.0000049 & 0.43 & 0.92 & 0.304 \\
\hline \multicolumn{2}{|c|}{ Target } & 0 & 0 & 0 & 10 & 10 & 10 & 20 & 20 & 0 & 30 & 30 & 30 & 40 & 40 & 0 \\
\hline
\end{tabular}

\begin{tabular}{|c|c|c|c|c|c|c|c|c|c|c|c|c|c|c|c|}
\hline Target & 0 & 0 & 0 & 10 & 10 & 10 & 20 & 20 & 0 & 30 & 30 & 30 & 40 & 40 & 0 \\
\hline Network Result & 0.00 & 0.00 & 0.00 & 9.73 & 9.96 & 9.94 & 19.93 & 19.91 & 0.00 & 29.99 & 29.99 & 29.99 & 40.00 & 40.00 & 0.00 \\
\hline Error \% & 0.00 & 0.00 & 0.00 & 26.58 & 4.00 & 6.34 & 6.93 & 8.80 & 0.00 & 1.13 & 1.27 & 1.23 & 0.11 & 0.00 & 0.00 \\
\hline
\end{tabular}


Table 29: Training Data and Result with 50\% DG for 3-phase Fault and LL Fault

\begin{tabular}{|c|c|c|c|c|c|c|c|c|c|c|c|c|c|c|c|c|}
\hline \multicolumn{2}{|r|}{ Data } & \multicolumn{3}{|c|}{ No Fault } & \multicolumn{3}{|c|}{ 3-Ph Fault @ Z2 } & \multicolumn{3}{|c|}{ LL Fault @ Z2 } & \multicolumn{3}{|c|}{ 3-Ph Fault @Z5 } & \multicolumn{3}{|c|}{ LL Fault @Z5 } \\
\hline \multirow[t]{2}{*}{ Zone 2} & I1e & 31.27 & 26.24 & 27.65 & 741.1 & 740.9 & 741.1 & 649.2 & 634.6 & 27.65 & 154.9 & 152.9 & 153.2 & 142.6 & 125.6 & 27.56 \\
\hline & $12 \mathrm{e}$ & 25.94 & 24.91 & 27.48 & 265.8 & 267.2 & 266.2 & 218.2 & 242.4 & 27.47 & 151.3 & 152.2 & 152.4 & 138.1 & 125.8 & 27.36 \\
\hline \multirow[t]{2}{*}{ Zone 5} & $14 \mathrm{~s}$ & 11.15 & 6.87 & 10.15 & 4.73 & 2.9 & 4.29 & 7.86 & 3.59 & 10.17 & 319.2 & 319.4 & 319.7 & 280.5 & 272.4 & 10.19 \\
\hline & $15 e$ & 0.88 & 1.93 & 0.31 & 0.37 & 0.81 & 0.13 & 0.62 & 1.01 & 0.313 & 0.000016 & 0.000034 & 0.0000057 & 0.45 & 0.95 & 0.314 \\
\hline \multicolumn{2}{|c|}{ Target } & 0 & 0 & 0 & 10 & 10 & 10 & 20 & 20 & 0 & 30 & 30 & 30 & 40 & 40 & 0 \\
\hline
\end{tabular}

\begin{tabular}{|c|c|c|c|c|c|c|c|c|c|c|c|c|c|c|c|}
\hline Target & 0 & 0 & 0 & 10 & 10 & 10 & 20 & 20 & 0 & 30 & 30 & 30 & 40 & 40 & 0 \\
\hline Network Result & 0.00 & 0.00 & 0.00 & 9.75 & 10.45 & 9.32 & 19.80 & 19.99 & 0.00 & 30.02 & 30.01 & 30.01 & 39.99 & 39.99 & 0.00 \\
\hline Error \% & -0.03 & -0.27 & 0.00 & 24.81 & -45.36 & 67.82 & 20.00 & 1.00 & 0.00 & -2.00 & -1.00 & -1.00 & 1.00 & 1.00 & 0.00 \\
\hline
\end{tabular}

Table 30: Training Data and Result with 75\% DG for 3-phase Fault and LL Fault

\begin{tabular}{|c|c|c|c|c|c|c|c|c|c|c|c|c|c|c|c|c|}
\hline \multicolumn{2}{|r|}{ Data } & \multicolumn{3}{|c|}{ No Fault } & \multicolumn{3}{|c|}{ 3-Ph Fault @ Z2 } & \multicolumn{3}{|c|}{ LL Fault @ Z2 } & \multicolumn{3}{|c|}{ 3-Ph Fault @Z5 } & \multicolumn{3}{|c|}{ LL Fault @Z5 } \\
\hline \multirow[t]{2}{*}{ Zone 2} & I1e & 17.82 & 14.03 & 14.28 & 741.1 & 740.9 & 741.1 & 647.1 & 636.5 & 14.3 & 154.9 & 152.9 & 153.2 & 139.9 & 127.4 & 14.22 \\
\hline & $12 \mathrm{e}$ & 12.44 & 12.52 & 14.19 & 341.9 & 343.1 & 342.5 & 290.1 & 302.6 & 14.21 & 151.3 & 152.5 & 152.4 & 135.3 & 127.8 & 14.16 \\
\hline \multirow[t]{2}{*}{ Zone 5} & $14 \mathrm{~s}$ & 25.45 & 28.88 & 26.31 & 146.3 & 149.2 & 147.3 & 126.8 & 127.8 & 26.25 & 319.1 & 319.4 & 319.7 & 273.9 & 279.6 & 26.13 \\
\hline & $15 e$ & 34.39 & 28.01 & 33.86 & 152.4 & 148 & 152.4 & 138.4 & 123.9 & 33.8 & 468.6 & 468.5 & 468.6 & 417.1 & 395.2 & 33.76 \\
\hline \multicolumn{2}{|c|}{ Target } & 0 & 0 & 0 & 10 & 10 & 10 & 20 & 20 & 0 & 30 & 30 & 30 & 40 & 40 & 0 \\
\hline
\end{tabular}

\begin{tabular}{|c|c|c|c|c|c|c|c|c|c|c|c|c|c|c|c|}
\hline Target & 0 & 0 & 0 & 10 & 10 & 10 & 20 & 20 & 0 & 30 & 30 & 30 & 40 & 40 & 0 \\
\hline Network Result & 0.00 & 0.00 & 0.00 & 10.00 & 10.00 & 10.00 & 20.00 & 20.00 & 0.00 & 30.00 & 30.04 & 30.00 & 40.00 & 40.00 & 0.00 \\
\hline Error \% & 0.00 & 0.00 & 0.00 & 0.00 & 0.00 & 0.00 & 0.00 & 0.00 & 0.00 & 0.00 & -4.00 & 0.00 & 0.00 & 0.00 & 0.00 \\
\hline
\end{tabular}


Table 31: Training Data and Result with no DG for 3-phase Fault through 10-ohm resistance

\begin{tabular}{|c|c|r|r|r|r|r|r|r|r|r|}
\hline & Data & \multicolumn{4}{|c|}{ No Fault } & \multicolumn{3}{|c|}{ 3-Ph Fault with 10 ohm@ Z2 } & \multicolumn{3}{|c|}{ 3-Ph Fault with 10 ohm @Z5 } \\
\hline \multirow{2}{*}{ Zone 2 } & I1e & 56.82 & 48.61 & 52.14 & 568.7 & 568.4 & 568.6 & 194.5 & 192.3 & 192.7 \\
\cline { 2 - 11 } & I2e & 52.18 & 47.77 & 51.45 & 15.38 & 13.9 & 15.25 & 191.4 & 192.1 & 191.9 \\
\hline \multirow{2}{*}{ Zone 5 } & $14 \mathrm{~s}$ & 9.89 & 6.27 & 9.07 & 2.9 & 1.8 & 2.65 & 183.7 & 184.3 & 184.6 \\
\cline { 2 - 11 } & $15 \mathrm{e}$ & 0.78 & 1.76 & 0.28 & 0.23 & 0.51 & 0.08 & 0.091 & 0.196 & 0.032 \\
\hline \multicolumn{2}{|c|}{ Target } & 0 & 0 & 0 & 50 & 50 & 50 & 60 & 60 & 60 \\
\hline
\end{tabular}

\begin{tabular}{|l|r|r|r|r|r|r|r|r|r|r|}
\hline Target & 0 & 0 & 0 & 50 & 50 & 50 & 60 & 60 & 60 & \\
\hline $\begin{array}{l}\text { Network } \\
\text { Result }\end{array}$ & 0.00 & 0.00 & 0.00 & 50.00 & 50.01 & 50.00 & 60.00 & 60.00 & 60.00 & \\
\hline Error \% & -0.03 & -0.27 & 0.00 & 0.00 & -1.00 & 0.20 & 0.00 & -0.30 & 0.00 & \\
\hline
\end{tabular}

Table 32: Training Data and Result with 25\% DG for 3-phase Fault through 10-ohm resistance

\begin{tabular}{|c|l|r|r|r|r|r|r|r|r|r|}
\hline & Data & \multicolumn{4}{|c|}{ No Fault } & \multicolumn{3}{|c|}{ 3-Ph Fault with 10 ohm@ Z2 } & \multicolumn{3}{|c|}{ 3-Ph Fault with 10 ohm @Z5 } \\
\hline \multirow{2}{*}{ Zone 2 } & I1e & 45.07 & 38.19 & 40.73 & 563.8 & 563.3 & 563.8 & 189.4 & 187.2 & 187.6 \\
\cline { 2 - 11 } & $12 \mathrm{e}$ & 40.03 & 37.11 & 40.26 & 36.85 & 39 & 37.27 & 186.2 & 187 & 186.7 \\
\hline \multirow{2}{*}{ Zone 5 } & $14 \mathrm{~s}$ & 10.79 & 6.69 & 9.84 & 5.349 & 3.292 & 4.857 & 251.5 & 252 & 252.3 \\
\cline { 2 - 11 } & $15 \mathrm{e}$ & 0.85 & 1.87 & 0.303 & 0.42 & 0.92 & 0.15 & 0.13 & 0.27 & 0.0446 \\
\hline \multicolumn{2}{|c|}{ Target } & 0 & 0 & 0 & 50 & 50 & 50 & 60 & 60 & 60 \\
\hline
\end{tabular}

\begin{tabular}{|l|r|r|r|r|r|r|r|r|r|r|}
\hline Target & 0 & 0 & 0 & 50 & 50 & 50 & 60 & 60 & 60 & \\
\hline $\begin{array}{l}\text { Network } \\
\text { Result }\end{array}$ & 0.00 & 0.00 & 0.00 & 50.05 & 50.00 & 50.00 & 60.13 & 60.00 & 60.00 & \\
\hline Error \% & -0.03 & -0.27 & 0.00 & -5.00 & 0.01 & 0.00 & -13.00 & -0.06 & 0.00 & \\
\hline
\end{tabular}


Table 33: Training Data and Result with 50\% DG for 3-phase Fault through 10-ohm resistance

\begin{tabular}{|c|c|r|r|r|r|r|r|r|r|r|}
\hline & Data & \multicolumn{4}{|c|}{ No Fault } & \multicolumn{3}{|c|}{ 3-Ph Fault with 10 ohm @ Z2 } & \multicolumn{3}{|c|}{ 3-Ph Fault with 10 ohm @Z5 } \\
\hline \multirow{2}{*}{ Zone 2 } & I1e & 31.27 & 26.24 & 27.65 & 544.5 & 544 & 544.5 & 144.3 & 142.1 & 142.2 \\
\cline { 2 - 12 } & I2e & 25.94 & 24.91 & 27.48 & 182.8 & 184.9 & 183.2 & 140.3 & 141.5 & 141.6 \\
\hline \multirow{2}{*}{ Zone 5 } & I4s & 11.15 & 6.87 & 10.15 & 7.122 & 4.376 & 6.466 & 289.6 & 289.8 & 290.1 \\
\cline { 2 - 11 } & I5e & 0.88 & 1.93 & 0.31 & 0.56 & 1.22 & 0.199 & 0.144 & 0.31 & 0.051 \\
\hline \multicolumn{2}{|c|}{ Target } & 0 & 0 & 0 & 50 & 50 & 50 & 60 & 60 & 60 \\
\hline
\end{tabular}

\begin{tabular}{|l|r|r|r|r|r|r|r|r|r|r|}
\hline Target & 0 & 0 & 0 & 50 & 50 & 50 & 60 & 60 & 60 & \\
\hline $\begin{array}{l}\text { Network } \\
\text { Result }\end{array}$ & 0.00 & 0.00 & 0.00 & 50.06 & 50.00 & 50.00 & 60.01 & 60.00 & 60.00 & \\
\hline Error\% & -0.03 & -0.28 & 0.00 & -5.68 & 0.00 & 0.31 & -0.98 & -0.45 & 0.00 & \\
\hline
\end{tabular}

Table 34: Training Data and Result with 75\% DG for 3-phase Fault through 10-ohm resistance

\begin{tabular}{|c|c|r|r|r|r|r|r|r|r|r|}
\hline & Data & \multicolumn{4}{|c|}{ No Fault } & \multicolumn{3}{|c|}{ 3-Ph Fault with 10 ohm@ Z2 } & \multicolumn{3}{|c|}{ 3-Ph Fault with 10 ohm @Z5 } \\
\hline \multirow{2}{*}{ Zone 2 } & I1e & 31.27 & 26.24 & 27.65 & 530.7 & 530.2 & 530.6 & 134.6 & 132.3 & 132.2 \\
\cline { 2 - 12 } & I2e & 25.94 & 24.91 & 27.48 & 237.6 & 238.9 & 238 & 130.2 & 131.4 & 131.8 \\
\hline \multirow{2}{*}{ Zone 5 } & I4s & 11.15 & 6.87 & 10.15 & 111 & 114.3 & 112 & 262.4 & 262.7 & 264 \\
\cline { 2 - 11 } & I5e & 0.88 & 1.93 & 0.31 & 119.3 & 114.3 & 119.3 & 401.9 & 401.4 & 402 \\
\hline \multicolumn{2}{|c|}{ Target } & 0 & 0 & 0 & 50 & 50 & 50 & 60 & 60 & 60 \\
\hline
\end{tabular}

\begin{tabular}{|l|r|r|r|r|r|r|r|r|r|r|}
\hline Target & 0 & 0 & 0 & 50 & 50 & 50 & 60 & 60 & 60 & \\
\hline $\begin{array}{l}\text { Network } \\
\text { Result }\end{array}$ & 0.00 & 0.00 & 0.00 & 50.00 & 50.00 & 50.00 & 60.00 & 60.00 & 59.99 & \\
\hline Error \% & -0.02 & -0.37 & -0.01 & -0.33 & 0.00 & 0.00 & -0.29 & 0.00 & 1.00 & \\
\hline
\end{tabular}


Table 35: Training Data and Result with no DG for single phase to ground Fault

\begin{tabular}{|c|c|c|c|c|c|c|c|c|c|c|}
\hline & Data & \multicolumn{3}{|c|}{ No Fault } & \multicolumn{3}{|c|}{ SL-G Fault @Z2 } & \multicolumn{3}{|c|}{ SL-G Fault @Z5 } \\
\hline \multirow[t]{2}{*}{ Zone 2} & $11 \mathrm{e}$ & 56.82 & 48.61 & 52.14 & 553.2 & 51.76 & 55.17 & 156.1 & 52.52 & 55.65 \\
\hline & $12 \mathrm{e}$ & 52.18 & 47.77 & 51.45 & 9.584 & 50.74 & 54.67 & 153.6 & 51.77 & 55.13 \\
\hline \multirow[t]{2}{*}{ Zone 5} & $14 \mathrm{~s}$ & 9.89 & 6.27 & 9.07 & $\begin{array}{r}0.843 \\
5\end{array}$ & 7.183 & 9.887 & 146.3 & 7.512 & 10.06 \\
\hline & $15 e$ & 0.78 & 1.76 & 0.28 & $\begin{array}{r}0.065 \\
53 \\
\end{array}$ & 2.027 & 0.3084 & 0.0059 & 2.131 & 0.3142 \\
\hline \multicolumn{2}{|c|}{ Target } & 0 & 0 & 0 & 70 & 0 & 0 & 80 & 0 & 0 \\
\hline
\end{tabular}

\begin{tabular}{|l|r|r|r|r|r|r|r|r|r|r|}
\hline Target & 0 & 0 & 0 & 70 & 0 & 0 & 80 & 0 & 0 & \\
\hline $\begin{array}{l}\text { Network } \\
\text { Result }\end{array}$ & 0.00 & 0.00 & 0.00 & 70.00 & 0.00 & 0.00 & 80.00 & 0.00 & 0.00 & \\
\hline Error \% & 0.00 & 0.00 & 0.00 & 0.00 & 0.00 & 0.00 & 0.00 & 0.00 & 0.00 & \\
\hline
\end{tabular}

Table 36: Training Data and Result with 25\% DG for single phase to ground Fault

\begin{tabular}{|l|l|r|r|r|r|r|r|r|r|r|}
\hline & Data & \multicolumn{3}{|c|}{ No Fault } & \multicolumn{3}{|c|}{ SL-G Fault @Z2 } & \multicolumn{3}{|c|}{ SL-G Fault @Z5 } \\
\hline \multirow{2}{*}{ Zone 2 } & I1e & 45.07 & 38.19 & 40.73 & 551.4 & 40.03 & 47.75 & 154.9 & 41.04 & 55.26 \\
\cline { 2 - 12 } & I2e & 40.03 & 37.11 & 40.26 & 54.62 & 38.96 & 47.48 & 152.3 & 40.48 & 55.03 \\
\hline \multirow{2}{*}{ Zone 5 } & $14 \mathrm{~s}$ & 10.79 & 6.69 & 9.84 & 3.913 & 7.194 & 9.861 & 227.4 & 7.721 & 10.24 \\
\cline { 2 - 11 } & I5e & 0.85 & 1.87 & 0.303 & 0.307 & 2.025 & 0.306 & 0.0056 & 2.194 & 0.3194 \\
& & & & & 3 & & & & & 0 \\
\hline \multicolumn{2}{|c|}{ Target } & 0 & 0 & 0 & 70 & 0 & 0 & 80 & 0 & 0 \\
\hline
\end{tabular}

\begin{tabular}{|l|r|r|r|r|r|r|r|r|r|r|}
\hline Target & 0 & 0 & 0 & 70 & 0 & 0 & 80 & 0 & 0 & \\
\hline $\begin{array}{l}\text { Network } \\
\text { Result }\end{array}$ & 0.00 & 0.00 & 0.00 & 70.00 & 0.00 & 0.00 & 79.99 & 0.00 & 0.00 & \\
\hline Error \% & 0.00 & 0.00 & 0.00 & 0.00 & 0.00 & 0.00 & 1.00 & 0.00 & 0.00 & \\
\hline
\end{tabular}


Table 37: Training Data and Result with 50\% DG for single phase to ground Fault

\begin{tabular}{|c|c|c|c|c|c|c|c|c|c|c|}
\hline & Data & & No Faul & & & -G Fault & & & Fault & \\
\hline \multirow[t]{2}{*}{ Zone 2} & I1e & 31.27 & 26.24 & 27.65 & 555.1 & 35.56 & 49.34 & 111 & 30.41 & 46.14 \\
\hline & $12 \mathrm{e}$ & 25.94 & 24.91 & 27.48 & 223.7 & 34.97 & 49.57 & 107.5 & 29.99 & 46.24 \\
\hline \multirow[t]{2}{*}{ Zone 5} & $14 \mathrm{~s}$ & 11.15 & 6.87 & 10.15 & 5.966 & 6.971 & 9.95 & 263.4 & 7.875 & 10.59 \\
\hline & $15 e$ & 0.88 & 1.93 & 0.31 & $\begin{array}{r}0.469 \\
7\end{array}$ & 1.96 & 0.3078 & $\begin{array}{r}0.00576 \\
5\end{array}$ & 2.24 & 0.3305 \\
\hline \multicolumn{2}{|c|}{ Target } & 0 & 0 & 0 & 70 & 0 & 0 & 80 & 0 & 0 \\
\hline
\end{tabular}

\begin{tabular}{|l|r|r|r|r|r|r|r|r|r|r|}
\hline Target & 0 & 0 & 0 & 70 & 0 & 0 & 80 & 0 & 0 & 0.00 \\
\hline $\begin{array}{l}\text { Network } \\
\text { Result }\end{array}$ & 0.00 & 0.00 & 0.00 & 70.00 & 0.00 & 0.00 & 80.00 & 0.00 & 0.00 \\
\hline Error \% & 0.00 & 0.00 & 0.00 & 0.00 & 0.00 & 0.00 & 0.00 & 0.00 & 0.00 & \\
\hline
\end{tabular}

Table 38: Training Data and Result with $75 \%$ DG for single phase to ground Fault

\begin{tabular}{|c|c|r|r|r|r|r|r|r|r|r|}
\hline & Data & \multicolumn{3}{|c|}{ No Fault } & \multicolumn{3}{|c|}{ SL-G Fault @Z2 } & \multicolumn{3}{c|}{ SL-G Fault @Z5 } \\
\hline \multirow{2}{*}{ Zone 2 } & I1e & 31.27 & 26.24 & 27.65 & 548.2 & 21.43 & 30.39 & 114.5 & 29.85 & 43.12 \\
\cline { 2 - 12 } & I2e & 25.94 & 24.91 & 27.48 & 272.6 & 20.85 & 30.87 & 110.9 & 30.17 & 43.56 \\
\hline \multirow{2}{*}{ Zone 5 } & I4s & 11.15 & 6.87 & 10.15 & 107.5 & 31.06 & 33.96 & 267.5 & 27.14 & 30.5 \\
\cline { 2 - 11 } & I5e & 0.88 & 1.93 & 0.31 & 113.1 & 28.06 & 42.44 & 458.6 & 33.08 & 26.89 \\
\hline \multicolumn{2}{|c}{ Target } & 0 & 0 & 0 & 70 & 0 & 0 & 80 & 0 & 0 \\
\hline
\end{tabular}

\begin{tabular}{|l|r|r|r|r|r|r|r|r|r|r|}
\hline Target & 0 & 0 & 0 & 70 & 0 & 0 & 80 & 0 & 0 & 0.00 \\
\hline $\begin{array}{l}\text { Network } \\
\text { Result }\end{array}$ & 0.00 & 0.00 & 0.00 & 70.01 & 0.00 & 0.00 & 80.00 & 0.00 & 0.00 & 0.00 \\
\hline Error \% & 0.00 & 0.00 & 0.00 & -1.00 & 0.00 & 0.00 & -0.10 & 0.00 \\
\hline
\end{tabular}


The Artificial Neural Network results indicate that this method can be used for detecting the faults, and it is reliable to find the location of the faults. This method tends to fail when the number of zones is connected, as it requires more training. Training the network has to be done more than one time to get the best results possible. The ANN has been divided into four smaller Neural Networks as the power supplied by the DGs in the power system changes.

This method can be used to detect the faults location, but network retraining is needed each time when the power supplied by the DGs is different. Also when training the network, introducing the fault is mandatory for the network to detect the change in the PS when a fault occurs. Training is needed before using the ANN. This is the main disadvantage of using the Artificial Networks. 


\section{Chapter 6}

\section{Conclusion and Future Work}

The present fault identification methods are not reliable if the load power is supplied by the DGs. Some methods will work if the power supplied by the DGs is small. Different methods have different advantages and disadvantages according to their way of implementation in the PS. Applying DGs into the PS will affect the methods used to identify the location of the faults.

\subsection{Conclusion}

In this thesis, different methods have been tested for the IEEE 34 Node Test Feeder while different amounts of the load power are supplied by DGs to determine if these methods will fail. The proposed methods are:

- Change of Current Method

- Symmetrical Components

- Artificial Neural Networks

The test feeder was modeled in MATLAB and the proposed methods were tested. Different types of faults were introduced in the system, and the data was 
gathered from each zone in the system and analyzed in all of the scenarios of load power supplied by the DGs.

The different fault types and locations have a different effect on the data in each method. The data was obtained by repeating the tests for several times. All the possible cases were studied during the testing of the system.

Change of current method was able to detect the fault in both zones (2 and 5) until the load power injected by the DGs reached 50\%. After the load power injected by the DGs reached $50 \%$, this method failed in identifying the location of the fault. If the fault is single phase to ground, the method will be able to detect the location up to $75 \%$ of power injected by the DGs.

Symmetrical components method was able to detect the three-phase fault even when we injected the PS with power from DGs, but the method failed in detecting the location of LL fault. For the three phase fault through 10-ohm resistance the method was able to find the location when the fault occurred in zone 2 only. While for the single line to ground fault the method was able to detect the location of the fault when the power injected by the DGs was less than $75 \%$.

ANN was able to find the location of all of the fault types tested in the system, but the network needed training for each time when the system power was injected through DGs. 


\subsection{Future Work}

The methods of identifying the location of the faults are being looked at as one of the main research areas in power systems. Introducing new methods that can be more reliable is a great area of research. A lot of future work can be done in this area, as it is a challenging area of research in electrical engineering. Some of the future work is suggested to be done in this thesis is listed below:

- The next stage is to focus on introducing a new algorithm for finding the location of the faults with a different amount of load power supplied by the DGs.

- Combining existing methods together in trying to eliminate the disadvantages of each method.

- Introducing a new Hybrid method that combines two methods to work together simultaneously.

- Improving the existing methods to rely on them even if we have a high percentage of the load power is supplied by the DGs to the system.

- Focusing on exact identifying the location of the faults rather than identifying the zone only.

- Improving the identifying algorithms for identifying more than one fault that might happen at the same time. 


\section{References}

[1] Jawad Ghorbani, "A multi-Agent Design for Power Distribution Systems Automation", Doctoral Dissertation, West Virginia University, 2014

[2] Seetaram Alwala, "Multi-Agent System Based Fault Location in a Smart MicroGrid System ", M.S Thesis, West Virginia University, 2011

[3] Pituk Bunnoon, "Fault Detection Approaches to Power System: State-of-theArt Article Reviews for Searching a New Approach in the Future ", International Journal of Electrical and Computer Engineering (IJECE), Vol. 3, No. 4, August 2013, pp. 553-560.

[4] M. Mirzaei, M.Z. A Ab Kadir, E. Moazami, H. Hizam, "Review of Fault Location Methods for Distribution Power System", Australian Journal of Basic and Applied Sciences, 3(3), 2009

[5] Rodrigo Hartstein Salim, Karen Rezende Caino de Oliveira, André Darós Filomena, Mariana Resener, Arturo Suman Bretas, "Hybrid Fault Diagnosis Scheme Implementation for Power Distribution Systems Automation", IEEE Transactoin on Power Delivery, Vol. 23, No. 4, October 2008

[6] Distribution System Analysis Subcommittee Report, "Radial Distribution Test Feeders", http://ewh.ieee.org/soc/pes/dsacom/testfeeders/

[7] "Northeast blackout of 2003", https://en.wikipedia.org/wiki/Northeast blackout of 2003

[8] Hashim Abbas M. Al Hassan, "Fault Location Identification For A VSX-HVDC System with a Long Hybrid Transmission Medium", M.S Thesis, University of Pittsburgh, 2010

[9] Sidharth Parmar Ashok, "Modeling and Protection Scheme for IEEE 34 Radial Distribution Feeder with and without Distributed Generation", M.S Thesis, The University of Wisconsin-Milwaukee, 2014.

[10] U.S. Department of Energy, "The Potential Benefits of Distributed Generation and Rate-Related Issues that may Impede their Expansion ",A study pursuant to section 1817 of the energy policy act of 2005, February 2007 
[11] Saptarshi Roy, Dr. P. Suresh Bab, "Accurate Fault Location Identification on Series Compensated Transmission Line", International Journal For Technological Research In Engineering Vol 1, Issue 8, April-2014

[12] Shimaa Hassan Sayed Barakat, "Fault detection, classification and location in Underground Cables", M.S Thesis, Fayoum University, Egypt , 2014

[13] Ying-Yi Hong, Yan-Hung Wei, Yung-Ruei Chang, Yih-Der Lee, PangWei Liu, "Fault Detection and Location by Static Switches in Microgrids Using Wavelet Transform and Adaptive Network-Based Fuzzy Inference System", Energies, Vol. 7, Issue. 4, 2014, www.mdpi.com/journal/energies

[14] Zhihan Xu, "Fault Location and Incipient Fault Detection in Distribution Cables", M.S Thesis, The University of Western Ontario, 2011

[15] David Gomes, Richard Colunga, "Distribution Automation Case Study: Rapid Fault Detection, Isolation, and Power Restoration for a Reliable Underground Distribution System", 68th Annual Conference for Protective Relay Engineers, March 2015

[16] J. Mora, J. Meléndez, Marc Vinyoles, J. Sánchez, Manel Castro, "An overview of fault location methods in distribution system based on single end measures of voltage and current", University of Girona

[17] Nelson Manuel Brito Costa Pereira, "Electric Fence Fault Detection and Location", M.S Thesis, University of Porto, 2010

[18] Surender Kumar Yellagoud, Munjuluri Sree Harsha, Bhamidipati Sridhar, "More Accurate and Fast Fault Identification on Power Networks Using Artificial Neural Networks", International Journal of Engineering and Advanced Technology (IJEAT), Vol. 2, Issue. 5, June 2013

[19] Seema Singh, Mamatha K R,Thejaswini S, "Intelligent Fault Identification System for Transmission Lines Using Artificial Neural Network", IOSR Journal of Computer Engineering (IOSR-JCE) , Vol. 16, Issue. 1, Ver. I (Jan. 2014), PP 23-31

[20] ZUBER N, Bajric R, Šostakov R, "Gearbox Faults Identification Using Vibration Signal Analysis and Artificial Intelligence Methods", Eksploatacja I Niezawodnosc - Maintenance and Reliability VOL.16, NO. 1, 2014 
[21] Abdolhamid Rahideh, Mohsen Gitizadeh, Sirus Mohammadi, "A Fault Location Technique for Transmission Lines Using Phasor Measurements", International Journal of Engineering and Advanced Technology (IJEAT), Vol .3, Issue .1, October 2013

[22] Choowong-Wattanasakpubal, Teratum-Bunyagul, "Algorithm for Detecting, Identifying, Locating and Experience to Develop the Automate Faults Location in Radial Distribution System", Journal of Electrical Engineering \& Technology Vol. 5, No. 1, 2010, pp. 36 44

[23] Yuan Liao, Mladen Kezunovic, "Optimal Estimate of Transmission Line Fault Location Considering Measurement Errors", IEEE Transaction on Power Delivery, Vol. 22, No. 3, JULY 2007

[24] Xiaodong Liang, Scott A. Wallace, Xinghui Zhao, "A Technique for Detecting Wide-Area Single-Line- To-Ground Faults", Washington State University

[25] Magnus $\mathrm{O}$ " hrstro "m, "Fast fault detection for power distribution systems", Licentiate Thesis, Royal Institute of Technology, 2003 